\title{
Three-dimensional Eulerian modeling of gas-liquid-solid flow with gas hydrate dissociation in a vertical pipe
}

\author{
Peng Li, Xuhui Zhang*, Xiaobing Lu \\ Institute of Mechanics, Chinese Academy of Sciences, Beijing 100190, China \\ School of Engineering Science, University of Chinese Academy of Sciences, Beijing 100049, China
}

\section{H I G H L I G H T S}

- A three-dimensional transient Eulerian model was developed to describe the gas-liquid-solid flow with GH dissociation.

- The convective heat transfer was coupled with GH dissociation.

- The transition of the flow pattern occurred, leading to the bed expansion.

- The effect of GH saturation on the multiphase flow was predicted and discussed.

\section{A R T I C L E I N F O}

\section{Article history:}

Received 26 June 2018

Received in revised form 25 October 2018

Accepted 27 October 2018

Available online $\mathrm{xxxx}$

\section{Keywords:}

Marine gas hydrate-bearing sediment

Hydrate dissociation model

CFD

Gas-liquid-solid

Eulerian model

\begin{abstract}
A B S T R A C T
The pipe transportation of gas hydrate-bearing sediments $(\mathrm{GHBS})^{1}$ is one of the key problems in mechanical-thermal exploitation of gas hydrate $(\mathrm{GH})^{2}$ in marine stratum. It is a gas-liquid-solid (methane gas-seawater-GHBS particles) three-phase flow, accompanied by GH dissociation. In this study, a threedimensional Eulerian model combined with the kinetic theory of granular flow (KTGF) was adopted to simulate the gas-liquid-solid flow with GH dissociation. The commercial CFD software FLUENT 16.2 was employed, considering the hydrodynamics, heat and mass transfer, and $\mathrm{GH}$ dissociation simultaneously. A kinetic model for GH dissociation in the GHBS particles is presented, considering the influence of multiphase flow on dissociation rate. The model can capture the transition from the initial liquid-solid two-phase flow to gas-liquid-solid three-phase flow, describing the distribution of the phase volume fraction, velocity, temperature, and dissociation rate. The interaction between GH dissociation and multiphase flow is discussed. The simulation results indicate that the continuous production of gas bubbles by GH dissociation leads to more violent fluctuations in the pressure gradient and a more marked elevation of the solid particles compared with the liquid-solid two-phase flow without GH dissociation. In addition, the effect of GH dissociation on the multiphase flow under different hydrate saturations was analyzed.
\end{abstract}

(c) 2018 Elsevier Ltd. All rights reserved.

\section{Introduction}

Gas hydrate $(\mathrm{GH})$ is a kind of solid cage-type compound composed of hydrocarbon gases such as methane and water molecules. Gas hydrate-bearing sediments (GHBS) are widely distributed in the sea, permafrost, and deep lakes (Kvenvolden and Lorenson, 2001). In recent decades, GH has attracted extensive attention for its huge reserve of resources and small pollution compared to fossil fuels. Current methods for $\mathrm{GH}$ exploitation include the thermal

\footnotetext{
* Corresponding author.

E-mail addresses: lipeng@imech.ac.cn (P. Li), zhangxuhui@imech.ac.cn (X. Zhang), xblu@imech.ac.cn (X. Lu).

${ }^{1}$ GHBS-gas hydrate-bearing sediments;

2 GH-gas hydrate.
}

injection method, depressurization method, carbon dioxide displacement, and inhibitor injection method (Zhang and Lu, 2016). The trial exploitations of GH have been carried out in the permafrost and marine strata. The Messoyakha gas field is the first mineral deposit of $\mathrm{GH}$ that has been exploited commercially in the world, but the focus is on the oil and gas reservoirs at the bottom (Makogon et al., 2005). In the Mallik permafrost region of Canada, pilot production was carried out in 2002 and 2007 by combining the thermal injection method with depressurization method (Moridis et al., 2004). In the Alaska permafrost region of the United States, the trial production was carried out in 2012 by the combination of the thermal injection and depressurization methods. In 2013 and 2017, Japan conducted two trial productions of submarine gas hydrates (Zhang et al., 2017). These practices show that these methods can dissociate GH through the 


\section{Nomenclature}

A

$B_{0}$

c

$C$

$C_{D}$

$d$

$D_{i j}$

$D_{H}$

e

$E_{a}$

$\mathrm{Fr}$

$g$

$g_{0}$

$G_{k}$

$h$

H

I

$k$

$k_{\Theta s}$

K

l

L

M

$\mathrm{Nu}$

$P$

$\mathrm{Pr}$

Q

$r$

$R$

$R e$

$\operatorname{Re}_{\mathrm{DH}}$

$S$

$S_{i j}$

$t$

$T$

V

$v$ pre-exponential factor

Bond number

specific heat $\left(\mathrm{J} \mathrm{kg}^{-1} \mathrm{~K}^{-1}\right)$

concentration $\left(\mathrm{kmol} \mathrm{m}^{-3}\right)$

drag coefficient

diameter $(\mathrm{mm})$

strain tensor for solid phase $\left(\mathrm{s}^{-1}\right)$

hydraulic diameter $(\mathrm{m})$

coefficient of restitution

activation energy $\left(\mathrm{J} \mathrm{mol}^{-1}\right)$

Froude number

gravitational acceleration $\left(\mathrm{m} \mathrm{s}^{-2}\right)$

radial distribution coefficient

generation of turbulent kinetic energy $\left(\mathrm{kg} \mathrm{m}^{-1} \mathrm{~s}^{-3}\right)$ interphase heat - transfer coefficient $\left(\mathrm{J} \mathrm{kg}^{-1} \mathrm{~K}^{-1} \mathrm{~m}^{-2}\right)$

specific enthalpy $(\mathrm{J})$

turbulence intensity

rate constant

diffusion coefficient for granular energy $\left(\mathrm{kg} \mathrm{m}^{-1} \mathrm{~s}^{-1}\right)$

interphase exchange coefficient $\left(\mathrm{kg} \mathrm{m}^{-3} \mathrm{~s}^{-1}\right)$

turbulence scale (m)

characteristic size $(\mathrm{m})$

interphase momentum exchange $\left(\mathrm{kg} \mathrm{m}^{-2} \mathrm{~s}^{-2}\right)$

Nusselt number

pressure $(\mathrm{Pa})$

Prandtl number

interphase heat exchange $(\mathrm{J})$

reaction rate of hydrate dissociation $\left(\mathrm{kmol} \mathrm{m}^{-3} \mathrm{~s}^{-1}\right)$

universal gas constant $\left(\mathrm{J} \mathrm{mol}^{-1} \mathrm{~K}^{-1}\right)$

Reynolds number

turbulence Reynolds number

interphase mass source term

strain tensor

time (s)

temperature $(\mathrm{K})$

volume $\left(\mathrm{m}^{3}\right)$

velocity $\left(\mathrm{m} \mathrm{s}^{-1}\right)$

\section{Greek letters}

$\alpha \quad$ volume fraction

$\beta \quad$ temperature exponent

$\gamma \quad$ collisional dissipation of energy $\left(\mathrm{kg} \mathrm{m}^{-1} \mathrm{~s}^{-3}\right)$

$\delta \quad$ specularity coefficient

$\varepsilon \quad$ dissipation rate of turbulent kinetic energy $\left(\mathrm{m}^{2} \mathrm{~s}^{-3}\right)$

$\eta \quad$ rate exponent

$\Theta \quad$ granular temperature $\left(\mathrm{m}^{2} \mathrm{~s}^{-2}\right)$

I stress tensor

$\mathrm{I}_{2 D} \quad$ second invariant of the deviatoric stress tensor

$\kappa \quad$ turbulence kinetic energy $\left(\mathrm{m}^{2} \mathrm{~s}^{-2}\right)$

$\lambda$ thermal conductivity $\left(\mathrm{W} \mathrm{m}^{-1} \mathrm{~K}^{-1}\right)$

$\mu \quad$ shear viscosity (Pa s)

$\xi \quad$ bulk viscosity (Pa s)

$\rho \quad$ density $\left(\mathrm{kg} \mathrm{m}^{-3}\right)$

$\sigma \quad$ surface tension coefficient $\left(\mathrm{N} \mathrm{m}^{-1}\right)$

$\tau \quad$ stress tensor $(\mathrm{Pa})$

$\varphi \quad$ angle of internal friction (rad)

$\Phi$ transferrate of kinetic energy $\left(\mathrm{kg} \mathrm{m}^{-1} \mathrm{~s}^{-3}\right)$

Subscripts

col collision

drag drag force

e equilibrium

fr friction

g gas phase

$i, j \quad$ species/component

kin kinetic

$l \quad$ liquid phase

lift lift force

lam laminar flow

max maximum value

$s \quad$ solid phase

Tur turbulent flow

$\mathrm{Vm}$ added mass force

W wall

$x, y, z$ axis disturbance of temperature and pressure, but it is difficult to meet the demand for the heat transfer and exploitation efficiency in commercial exploitation.

An effective method for increasing the efficiency of GH exploitation is to utilize convective heat transfer instead of heat conduction. A method called mechanical-thermal exploitation was proposed by Zhang et al. (2014). The details of the method can be found in the literature. One of the key procedures in the mechanical-thermal exploitation is the multiphase flow transport containing GH dissociation in a vertical pipe. In this procedure, warm seawater is injected into the pipe to transport and heat the GHBS particles, which dissociate rapidly in the flowing warm water, releasing a large amount of methane gas. As a result, the initial solid-liquid two-phase flow transforms into gas-liquid-solid three-phase flow. Few experimental data are reported because of the complexity of the newly presented problem. Theoretical modeling and numerical simulation are required to understand the main characteristics and controlling parameters for the optimization in engineering design.

Because of the multiphase flow transport with GH dissociation is a newly presented problem in the area of exploitation of GH in the marine stratum, to the best of our knowledge, only a few studies on the numerical simulation for the pipe transportation of GHBS particles have been reported in the open literature. Wang and Sun (2009) and Wei et al. (2016) presented a multiphase flow model to simulate the $\mathrm{GH}$ formation and dissociation in the annular pipe, considering GH dissociation in the mass and momentum conservation equations and the dissociation enthalpy in the energy conservation equation. However, the interphase momentum and heat exchange were not considered in the model, and pure GH particles were regarded as the solid phase.

The pipe transportation of GHBS particles is a typical dense particle reaction system in which the heat and mass transfer is closely accompanied by the process of multiphase flow. The key issue of computational fluid dynamics (CFD) simulation for the particle reaction system is the coupling of heat and mass transfer with the multiphase flow. A multitude of studies has been conducted on this topic. A list of papers on the CFD study of the reaction systems are tabulated in Table 1. It can be seen that most CFD studies are based on the gas-solid or liquid-solid two-phase flow coupling with the heat and mass transfer. Numerous studies have applied the CFD approach to simulate the hydrodynamics of gas-liquidsolid flow. For instance, Panneerselvam et al. (2009) developed a three-dimensional model to simulate the local hydrodynamics of a gas-liquid-solid three-phase fluidized bed reactor, and the results showed good agreement the experimental data for the three-phase hydrodynamics. Baltussen et al. (2017) studied the effective drag acting on particles and bubbles using direct numerical simulations in dense gas-liquid-solid three-phase flows. Qin and Suckale (2017) developed a numerical model to investigate 
Table 1

Literature survey on CFD studies of the coupling of heat and mass transfer with multiphase flow.

\begin{tabular}{|c|c|c|c|}
\hline Authors & Multiphase flow system & Simulation approach & Heat and mass transfer \\
\hline Gerber et al. (2010) & Gas-solid two-phase flow & 2-D, Eulerian-Eulerian model & $\begin{array}{l}\text { Wood pyrolysis and char gasification in a } \\
\text { bubbling fluidized bed reactor }\end{array}$ \\
\hline Snider and Banerjee (2010) & $\begin{array}{l}\text { Gas-solid two-phase flow, solid particles as } \\
\text { catalyst }\end{array}$ & $\begin{array}{l}\text { 3-D, Eulerian-Lagrangian } \\
\text { model }\end{array}$ & Ozone decomposition \\
\hline Armstrong et al. (2011) & Gas-solid two-phase flow & 2-D, Eulerian-Eulerian model & $\begin{array}{l}\text { Coal gasification and influence of limestone } \\
\text { calcination }\end{array}$ \\
\hline Behjat et al. (2011) & $\begin{array}{l}\text { Gas-solid two-phase flow, solid particles as } \\
\text { catalyst }\end{array}$ & $\begin{array}{l}\text { 3-D, Eulerian-Lagrangian } \\
\text { model }\end{array}$ & $\begin{array}{l}\text { Catalytic cracking reaction and vaporization of } \\
\text { gas oil droplets }\end{array}$ \\
\hline Adamczyk et al. (2014) & Gas-solid two-phase flow & $\begin{array}{l}\text { 3-D, Eulerian-Lagrangian } \\
\text { model }\end{array}$ & $\begin{array}{l}\text { Coal oxy-fuel combustion process in an } \\
\text { experimental circulating fluidized bed }\end{array}$ \\
\hline Loha et al. (2014) & Gas-solid two-phase flow & $\begin{array}{l}\text { 3-D, Eulerian-Lagrangian } \\
\text { model }\end{array}$ & $\begin{array}{l}\text { Biomass gasification in a bubbling fluidized } \\
\text { bed }\end{array}$ \\
\hline Klimanek et al. (2015) & Gas-solid two-phase flow & $\begin{array}{l}\text { 3-D, Eulerian-Lagrangian } \\
\text { model }\end{array}$ & Coal gasification in circulating fluidized bed \\
\hline $\begin{array}{l}\text { Askaripour and Dehkordi } \\
\text { (2016) }\end{array}$ & Gas-solid two-phase flow & 2-D, Eulerian-Eulerian model & $\begin{array}{l}\text { Methane combustion in the tapered-in and } \\
\text { tapered-out fluidized bed reactors }\end{array}$ \\
\hline Baniasadi et al. (2018) & Liquid-solid two-phase flow & $\begin{array}{l}\text { 3-D, Eulerian-Lagrangian } \\
\text { model }\end{array}$ & Melting process of a packed bed of particles \\
\hline Wu et al. (2018) & Gas-solid two-phase flow & 3-D, Eulerian-Eulerian model & $\begin{array}{l}\text { Oxy-fuel combustion in a circulating fluidized } \\
\text { bed with warm flue gas recycling }\end{array}$ \\
\hline
\end{tabular}

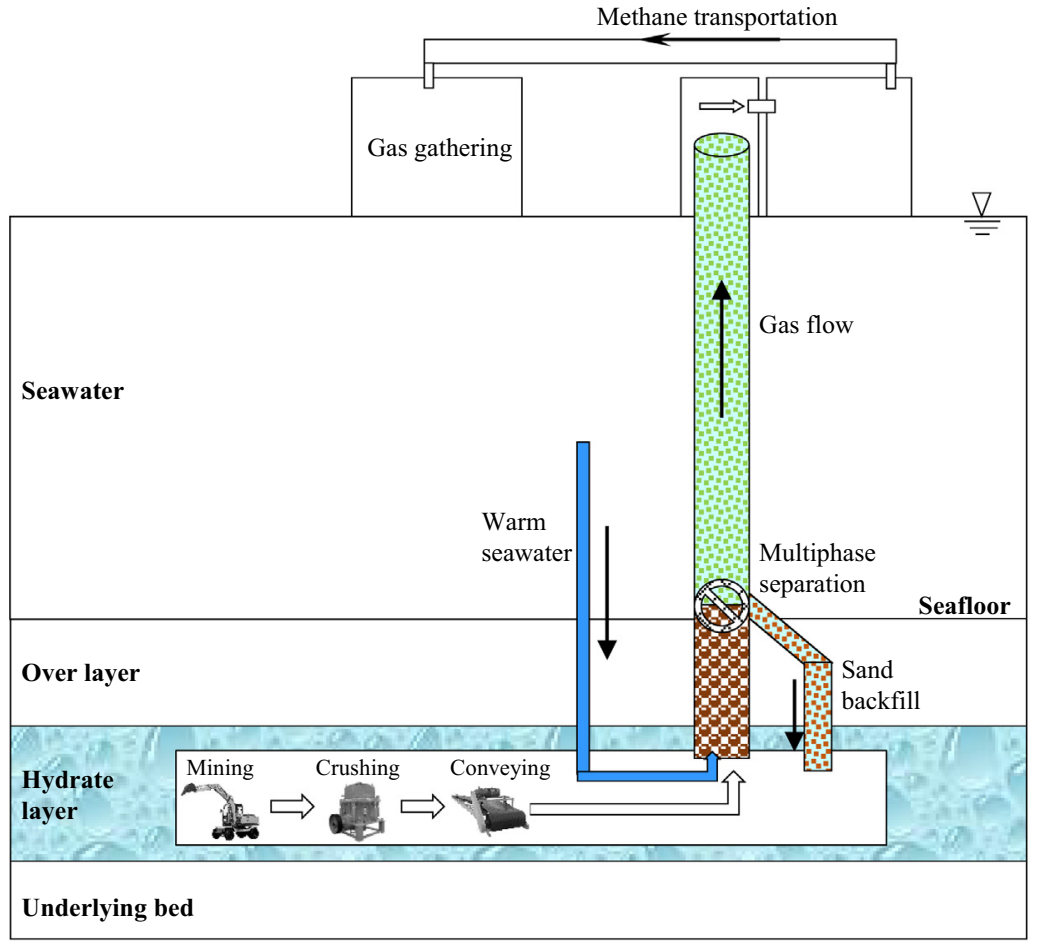

(a)

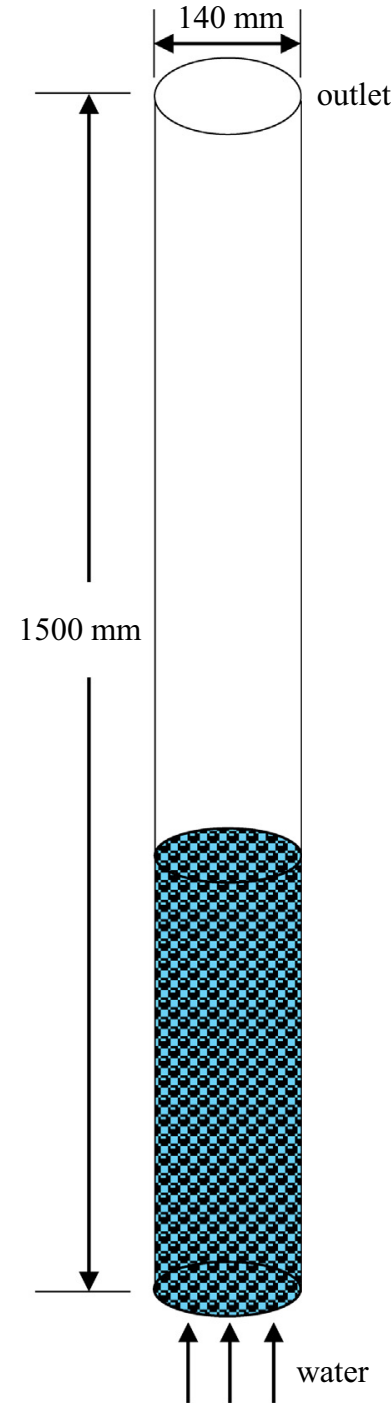

(b)

Fig. 1. (a) Schematic diagram of multiphase flow transport system containing GH dissociation in a vertical pipe. (b) The physical model for numerical simulation. 
Table 2

A summary of the governing equations and constitutive equations.

\begin{tabular}{l} 
A. Conservation equations \\
\hline (1) Mass conservation equations \\
(a) Gas phase \\
$\frac{\partial}{\partial t}\left(\alpha_{g} \rho_{g}\right)+\nabla \cdot\left(\alpha_{g} \rho_{g} \boldsymbol{v}_{g}\right)=S_{s g}(5)$ \\
(b) Liquid phase \\
$\frac{\partial}{\partial t}\left(\alpha_{l} \rho_{l}\right)+\nabla \cdot\left(\alpha_{l} \rho_{l} \boldsymbol{v}_{l}\right)=S_{s l}(6)$ \\
(c) Solid phase \\
$\frac{\partial}{\partial t}\left(\alpha_{s} \rho_{s}\right)+\nabla \cdot\left(\alpha_{s} \rho_{s} \boldsymbol{v}_{s}\right)=-S_{s g}-S_{s l}(7)$
\end{tabular}

(2) Momentum conservation equations

(a) Gas phase

$\frac{\partial}{\partial t}\left(\alpha_{g} \rho_{g} \boldsymbol{v}_{g}\right)+\nabla \cdot\left(\alpha_{g} \rho_{g} \boldsymbol{v}_{g} \boldsymbol{v}_{g}\right)=-\alpha_{g} \nabla P+\nabla \cdot \tau_{g}+\alpha_{g} \rho_{g} \mathbf{g}+M_{s g}+M_{l g}+S_{s g} \boldsymbol{v}_{s}$ (8)

(b) Liquid phase

$\frac{\partial}{\partial t}\left(\alpha_{l} \rho_{l} \boldsymbol{v}_{l}\right)+\nabla \cdot\left(\alpha_{l} \rho_{l} \boldsymbol{v}_{l} \boldsymbol{v}_{l}\right)=-\alpha_{l} \nabla P+\nabla \cdot \tau_{l}+\alpha_{l} \rho_{l} \boldsymbol{g}+M_{g l}+M_{s l}+S_{s l} \boldsymbol{v}_{s}(9)$

(c) Solid phase

$\frac{\partial}{\partial t}\left(\alpha_{s} \rho_{s} \boldsymbol{v}_{s}\right)+\nabla \cdot\left(\alpha_{s} \rho_{s} \boldsymbol{v}_{s} \boldsymbol{v}_{s}\right)=-\alpha_{s} \nabla P-\nabla P_{s}+\nabla \cdot \tau_{s}+\alpha_{s} \rho_{s} \mathbf{g}+M_{g s}+$

$M_{l s}-S_{s g} \boldsymbol{v}_{s}-S_{s l} \boldsymbol{v}_{s}(10)$

(d) Gas phase stress

$\tau_{g}=\alpha_{g} \mu_{g}\left(\nabla \boldsymbol{v}_{g}+\left(\nabla \boldsymbol{v}_{g}\right)^{\mathrm{T}}\right)(11)$

(e) Liquid phase stress

$\tau_{l}=\alpha_{l} \mu_{l}\left(\nabla \boldsymbol{v}_{l}+\left(\nabla \boldsymbol{v}_{l}\right)^{\mathrm{T}}\right)(12)$

(f) Solid phase stress

$\boldsymbol{\tau}_{s}=\alpha_{s} \mu_{s}\left(\nabla \boldsymbol{v}_{s}+\left(\nabla \boldsymbol{v}_{s}\right)^{\mathrm{T}}\right)+\alpha_{s}\left(\xi_{s}-\frac{2}{3} \mu_{s}\right) \nabla \cdot \boldsymbol{v}_{s} \mathbf{I}(13)$

(g) Liquid shear viscosity

$\mu_{l}=\mu_{\mathrm{lam}, l}+\mu_{\mathrm{tur}, l}(14)$

(h) Liquid turbulent viscosity

$\mu_{\mathrm{tur}, l}=\rho_{l} C_{\mu} \kappa_{l}^{2} / \varepsilon_{l}(15)$

(i) Turbulent kinetic energy equation

$\frac{\partial}{\partial t}\left(\alpha_{l} \rho_{l} \kappa\right)+\nabla \cdot\left(\alpha_{l} \rho_{l} \boldsymbol{v}_{l} \kappa\right)=\nabla \cdot\left(\alpha_{l} \frac{\mu_{\text {turl } l}}{\sigma_{\kappa}} \nabla \kappa\right)+\alpha_{l} G_{\kappa}-\alpha_{l} \rho_{l} \varepsilon(16)$

(j) Dissipation rate equation

$\frac{\partial}{\partial t}\left(\alpha_{l} \rho_{l} \varepsilon\right)+\nabla \cdot\left(\alpha_{l} \rho_{l} \boldsymbol{v}_{l} \varepsilon\right)=\nabla \cdot\left(\alpha_{l} \frac{\mu_{\text {tur. }, l}}{\sigma_{\varepsilon}} \nabla \varepsilon\right)+\alpha_{l} \frac{\varepsilon}{\kappa}\left(C_{1 \varepsilon} G_{\kappa}-C_{2 \varepsilon} \rho_{l} \varepsilon\right)(17)$

(k) Generation of turbulent kinetic energy due to the average velocity gradient

$G_{\kappa}=\mu_{\mathrm{tur}, l} \nabla \boldsymbol{v}_{l} \cdot\left[\left(\nabla \boldsymbol{v}_{l}+\left(\nabla \boldsymbol{v}_{l}\right)^{\mathrm{T}}\right)\right]-\frac{2}{3} \nabla \boldsymbol{v}_{l}\left(\mu_{\mathrm{tur}, l} \nabla \boldsymbol{v}_{l}+\rho_{l} \kappa\right)(18)$

(3) Energy conservation equations

(a) Gas phase

$\frac{\partial}{\partial t}\left(\alpha_{g} \rho_{g} H_{g}\right)+\nabla \cdot\left(\alpha_{g} \rho_{g} \boldsymbol{v}_{g} H_{g}\right)=-\alpha_{g} \frac{\partial P}{\partial t}+\tau_{g}: \nabla \boldsymbol{v}_{g}+\nabla\left(\lambda_{g} \nabla T_{g}\right)+S_{s g} H_{s g}$ (19)

(b) Liquid phase

$\frac{\partial}{\partial t}\left(\alpha_{l} \rho_{l} H_{l}\right)+\nabla \cdot\left(\alpha_{l} \rho_{l} \boldsymbol{v}_{l} H_{l}\right)=-\alpha_{l} \frac{\partial P}{\partial t}+\tau_{l}: \nabla \boldsymbol{v}_{l}+\nabla\left(\lambda_{l} \nabla T_{l}\right)+Q_{l s}+S_{s l} H_{s l}(20)$

(c) Solid phase

$\frac{\partial}{\partial t}\left(\alpha_{s} \rho_{s} H_{s}\right)+\nabla \cdot\left(\alpha_{s} \rho_{s} \boldsymbol{v}_{s} H_{s}\right)=-\alpha_{s} \frac{\partial P_{s}}{\partial t}+\tau_{s}: \nabla \boldsymbol{v}_{s}+\nabla\left(\lambda_{s} \nabla T_{s}\right)+$

$Q_{s l}-S_{s g} H_{s g}-S_{s l} H_{s l}(21)$

(d) Specific enthalpy of the gas and liquid phases

$H_{q}=\int c_{p, q} d T_{q}(22)$

(e) Specific enthalpy of the solid phase

$H_{s}=\sum_{i=1}^{3} Y_{i} H_{i}(23)$

(f) Thermal conductivity of liquid phase

$\lambda_{l}=\lambda_{\text {lam }, l}+\lambda_{\text {tur }, l}(24)$

(g) Turbulent thermal conductivity of liquid phase

$\lambda_{\text {tur }, l}=\frac{c_{p, l} \mu_{\text {tur }, l}}{\text { Pr }_{\text {tur.l }}}(25)$

(h) Heat exchange between the liquid and solid phases

$Q_{s l}=-Q_{l s}=h_{s l}\left(T_{s}-T_{l}\right)(26)$

(i) Heat-transfer coefficient between the fluid phase and the solid phase

$h_{s l}=\frac{6 \lambda_{l} \alpha_{s} \alpha_{l} N u_{s}}{d_{s}^{2}}(27)$

(j) Nusselt number

$N u_{s}=\left(7-10 \alpha_{l}+5 \alpha_{l}^{2}\right)\left(1+0.7 \operatorname{Re}_{s}^{0.2} \operatorname{Pr}^{1 / 3}\right)+\left(1.33-2.4 \alpha_{l}+\right.$

$\left.1.2 \alpha_{l}^{2}\right) \operatorname{Re}_{s}^{0.7} \operatorname{Pr}^{1 / 3}(28)$

(k) Prandtl number

$\operatorname{Pr}=\frac{c_{p, l} \mu_{l}}{\lambda_{l}}(29)$

B. Kinetic theory of granular flow

(a) Conservation of solid phase fluctuating energy

$\frac{3}{2}\left[\frac{\partial}{\partial t}\left(\rho_{s} \alpha_{s} \Theta_{s}\right)+\nabla \cdot\left(\rho_{s} \alpha_{s} \boldsymbol{v}_{s} \Theta_{s}\right)\right]=\left(-P_{s} \mathbf{I}+\tau_{s}\right): \nabla \boldsymbol{v}_{s}+\nabla \cdot\left(k_{\Theta s} \nabla \Theta_{s}\right)-$ $\gamma_{\Theta s}+\Phi_{l s}(30)$

(b) Collisional dissipation of solid phase fluctuating energy
Table 2 (continued)

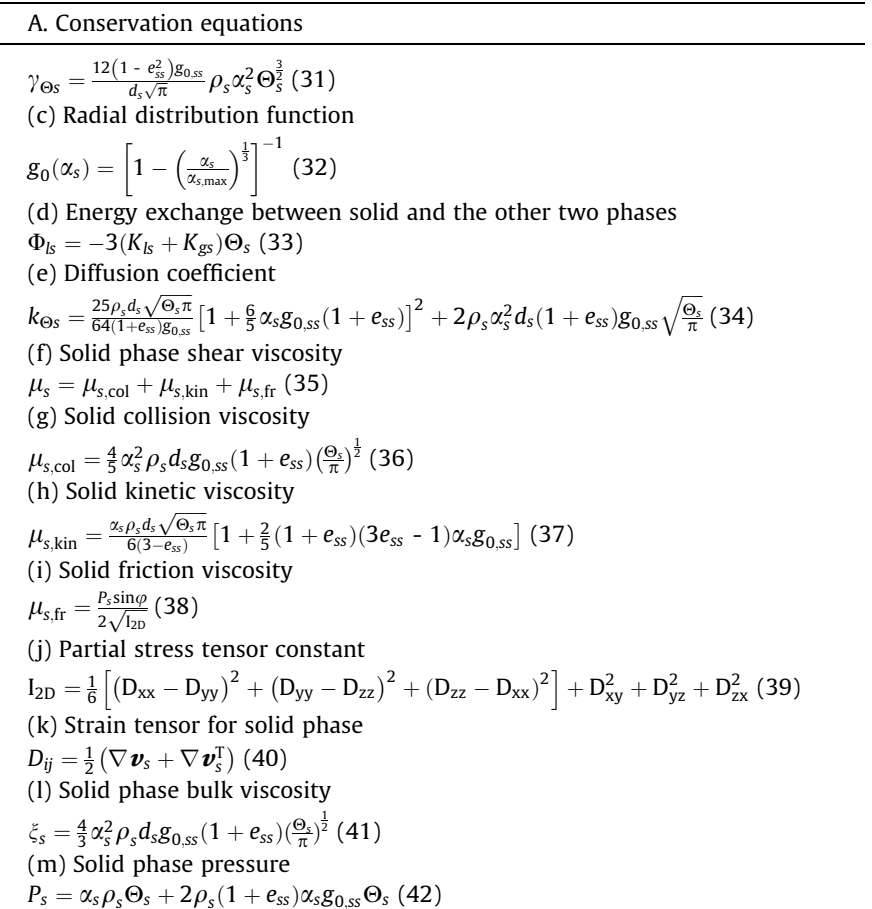

C. Interphase momentum exchange

(1) Liquid-solid interphase momentum exchange

(a) Liquid-solid interphase momentum exchange terms

$M_{l s}=K_{l s}\left(\boldsymbol{v}_{l}-\boldsymbol{v}_{s}\right)(43)$

$M_{s l}=K_{s l}\left(\boldsymbol{v}_{s}-\boldsymbol{v}_{l}\right)(44)$

(b) Interphase momentum exchange coefficient

$K_{l s}=\left\{\begin{array}{c}\alpha_{l} \geqslant 0.8, \frac{3}{4} C_{D, l s} \frac{\alpha_{s} \alpha_{l} \rho_{l}\left|\boldsymbol{v}_{s}-\boldsymbol{v}_{l}\right|}{d_{s}} \alpha_{l}^{-2.65} \\ \alpha_{l}<0.8,150 \frac{\alpha_{s}\left(1-\alpha_{l}\right) \mu_{l}}{\alpha_{l} d_{s}^{2}}+1.75 \frac{\rho_{l} \alpha_{s}\left|\boldsymbol{v}_{s}-\boldsymbol{v}_{l}\right|}{d_{s}}\end{array}\right.$

$C_{D, l s}=\left\{\begin{array}{c}0.44, R_{s}>1000 \\ \frac{24}{\alpha_{l} \operatorname{Re}_{s}}\left[1+0.15\left(\alpha_{l} R_{s}\right)^{0.687}\right], R e_{s} \leqslant 1000\end{array}\right.$

$\operatorname{Re}_{s}=\frac{\rho_{l} d_{s}\left|\boldsymbol{v}_{s}-\boldsymbol{v}_{l}\right|}{\mu_{l}}(47)$

(2) Gas-liquid interphase momentum exchange

(a) Gas-liquid interphase momentum exchange terms

$M_{g l}=K_{g l}\left(\boldsymbol{v}_{g}-\boldsymbol{v}_{l}\right)(48)$

$M_{l g}=K_{l g}\left(\boldsymbol{v}_{l}-\boldsymbol{v}_{g}\right)(49)$

(b) Interphase momentum exchange coefficient

$K_{g l}=\frac{3}{4} C_{D, g l} \rho_{l} \frac{\left|\boldsymbol{v}_{g}-\boldsymbol{v}_{l}\right|}{d_{g}}(50)$

$C_{D, g l}=\max \left(\min \left(\frac{24}{R e_{g}}\left(1+0.15 R e_{g}^{0.687}\right), \frac{72}{R e_{g}}\right), \frac{8}{3} \frac{B_{o}}{B_{o}+4}\right)$ (51)

(c) Bubble Reynolds number and Bond number

$\operatorname{Re}_{g}=\frac{\rho_{l}\left|\boldsymbol{v}_{\mathrm{g}}-\boldsymbol{v}_{\mid}\right| d_{g}}{\mu_{l}}(52)$

$B_{0}=\frac{g\left(\rho_{l}-\rho_{g}\right) d_{g}^{2}}{\sigma}(53)$

(3) Gas-solid interphase momentum exchange

(a) Gas-solid interphase momentum exchange terms

$M_{g s}=K_{g s}\left(\boldsymbol{v}_{g}-\boldsymbol{v}_{s}\right)(54)$

$M_{s g}=K_{s g}\left(\boldsymbol{v}_{s}-\boldsymbol{v}_{g}\right)(55)$

(b) Interphase momentum exchange coefficient

$$
\begin{aligned}
& K_{g s}=\left\{\begin{array}{c}
\alpha_{g} \geqslant 0.8, \frac{3}{4} C_{D, g s} \frac{\alpha_{s} \alpha_{g} \rho_{g}\left|\boldsymbol{v}_{s}-\mathbf{v}_{g}\right|}{d_{s}} \alpha_{g}^{-2.65} \\
\alpha_{g}<0.8,150 \frac{\alpha_{s}\left(1-\alpha_{g}\right) \mu_{g}}{\alpha_{g} d_{s}^{2}}+1.75 \frac{\rho_{g} \alpha_{s}\left|\boldsymbol{v}_{s}-\boldsymbol{v}_{g}\right|}{d_{s}}
\end{array}\right. \text { (56) } \\
& C_{D, g s}=\left\{\begin{array}{c}
0.44, \operatorname{Re}_{s}^{\prime}>1000 \\
\frac{24}{\alpha_{g} R e_{s}}\left[1+0.15\left(\alpha_{g} R e_{s}\right)^{0.687}\right], \operatorname{Re}_{s}^{\prime} \leqslant 1000
\end{array}\right. \\
& \operatorname{Re}_{s}^{\prime}=\frac{\rho_{g} d_{s}\left|\boldsymbol{v}_{s}-\boldsymbol{v}_{g}\right|}{\mu_{g}}(58)
\end{aligned}
$$

the three-phase interactions between gases, rigid bodies, and liquids in a dilute viscous fluid at variable temperature. Ma et al. (2018) developed an improved meso-scale flow model based on the energy minimum multi-scale (EMMS) theory to predict the global flow parameters of the gas-liquid-solid fluidized bed. However, most of the CFD simulations for the gas-liquid-solid flow is 
Table 3

Kinetic parameters of $\mathrm{GH}$ dissociation.

\begin{tabular}{llllll}
\hline$\eta$ & $A\left(\mathrm{kmol}^{1-\eta} \cdot \mathrm{s}^{-1}\right)$ & $\beta$ & $E_{a}(\mathrm{~J} / \mathrm{mol})$ & $R(\mathrm{~J} / \mathrm{mol} \cdot \mathrm{K})$ & $\Delta H_{\mathrm{dis}}(\mathrm{kJ} / \mathrm{mol})$ \\
\hline 0.6 & $3.89 \times 10^{12}$ & 2 & $9.83 \times 10^{4}$ & 8.314 & 54.5 \\
\hline
\end{tabular}

based on cold flow without taking heat and mass transfer into account (Pan et al., 2016). During the transportation of GHBS particles in the pipe, the initial solid-liquid two-phase flow gradually changes to the gas-liquid-solid three-phase flow due to GH dissociation. The gas phase comes from the solid particles, this transformation process is not involved in previous studies. Therefore, in the present study, the previous coupling method of two-phase flow with chemical reactions is extended to the gas-liquid-solid threephase flow system in order to investigate the transportation of GHBS particles. The momentum exchanges between the three phases after the gas is generated from the particles and the heat exchange between the liquid/gas and solid phases are considered. The Eulerian three-fluid model is adopted in this paper, as it is highly computationally efficient and can determine the main features of the pipe transportation of GHBS particles.

Many studies on GH dissociation have been carried out. In general, the dissociation rate includes the intrinsic dissociation rate, heat transfer rate, and mass transfer rate (Sean et al., 2007). Yin et al. (2016) provided a comprehensive review of the hydrate dissociation kinetic models, summarizing the formulation, assumptions, solution, and limitations of the kinetic models. The KimBishnoi dissociation model is regarded as the most classical and commonly used model to describe the GH dissociation process, in which the dissociation rate is dependent on temperature, pressure, and particle surface area. However, the Kim-Bishnoi model is constructed based on the mechanism of pure GH dissociation. It is not suitable for describing the GH dissociation in porous media (sediments) because it neglects the mass transfer rate. Since then, several theoretical models of GH dissociation have been developed within porous media under thermal injection and depressurization methods, containing heat and mass transfer rates. Selim and Sloan (1989) presented a physical model to describe hydrate dissociation under thermal stimulation in porous media. This model viewed the dissociation as a process whereby gas and water were produced at a moving boundary. Makogon (1997) considered that the hydrate dissociation in porous media occurred in a certain narrow area that was regarded as a surface and believed that the rate of hydrate dissociation was determined by the movement of the dissociation front. Hong et al. (2003) proposed a simple theoretical model to analyze hydrate dissociation in porous media. The dissociation rate was controlled by heat transfer, intrinsic kinetics, and gas-water two-phase flow. Oyama et al. (2009) presented a hydrate dissociation model in sediments that considered the heat transfer and deviation from phase equilibrium. However, none of the existing models on GH dissociation have considered the influences of continuously changing concentration, velocity, and temperature of the particles on the dissociation rate in the multiphase flow condition. Hence, in this paper, a GH dissociation rate model in Arrhenius form is presented, considering the influence of the particle concentration, the hydrate saturation, and the hydrate temperature on dissociation rate in multiphase flow. By coupling the dissociation model with the multiphase flow, the effect of the relative velocity between the water and particles on the dissociation rate is also considered.

The objective of this paper is to develop an efficient modeling methodology based on the Eulerian three-fluid model within the framework of the commercial CFD software FLUENT 16.2 to describe the gas-liquid-solid flow with the GHBS particle dissociation in a vertical pipe in the laboratory scale. In Section 2, the mathematical formulation of the gas-liquid-solid flow, heat and mass transfer, and $\mathrm{GH}$ dissociation are presented, including the continuity, momentum and energy conservation equations, kinetic model of granular flow, interphase momentum exchange, kinetic model of the GH dissociation, species transport equations, and initial and boundary conditions. In Section 3, the numerical modeling of the multiphase flow in the pipe is conducted. The simulated results are compared with the experimental data of Limtrakul et al. (2005). The distribution of the phase volume fraction, flow velocity, temperature, and pressure in the pipe are analyzed. The focus is on the interaction of GH dissociation and gas-liquid-solid flow. Meanwhile, the effects of GH saturation on the multiphase flow is discussed as well.

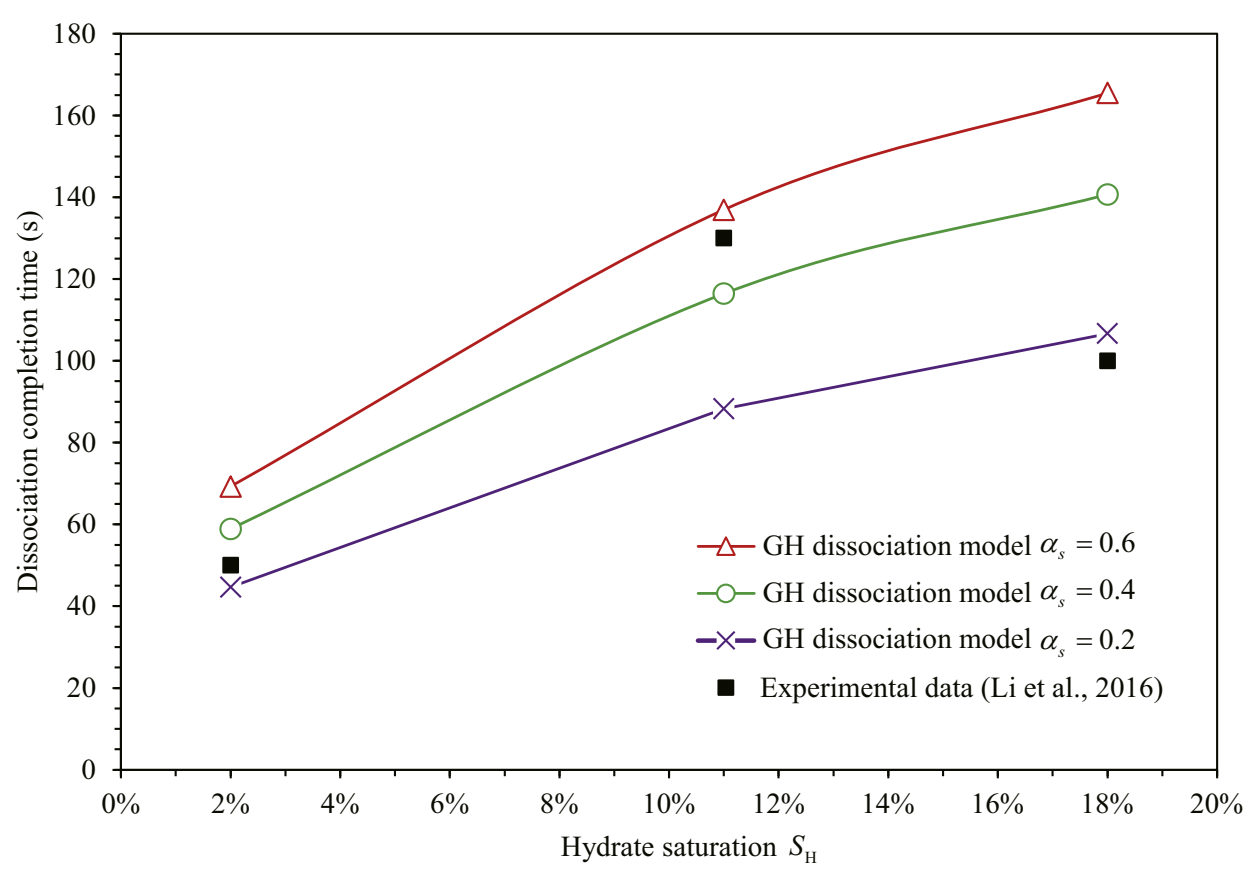

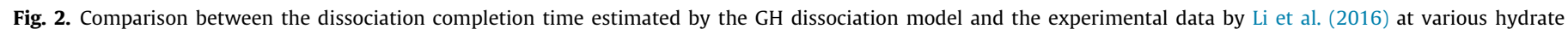
saturations. $P=0.1 \mathrm{MPa}, d_{s}=2 \mathrm{~cm}, T_{l}=303.15 \mathrm{~K}$, and $\phi=0.4$. 


\section{Methodology}

\subsection{Assumptions of the problem}

A schematic diagram of the problem is shown in Fig. 1a. The processes can be expressed as follows. First, particles are transferred from the mining zone into the pipe; second, warm seawater is continuously injected into the pipe from the bottom to lift and heat the GHBS particles; third, GH in the particles dissociates due to the heating of the seawater. During hydraulic lifting, the convective heat transfer between the GHBS particles and water leads to $\mathrm{GH}$ dissociation and the release of gas from GHBS particles. Hence, the liquid-solid two-phase flow transforms into gas-liquid-solid three-phase flow. With the increase in gas volume fraction, the pressure along the pipe redistributes; fourth, a multiphase separation system is set where GH decomposes completely. The soil particles are separated from the three-phase flow and transferred to backfill. The gas flows upwards to the gathering installation. It should be noted that the mining of the GHBS stratum, soil separation, and upward flow of gas are out of scope of this paper and will not be discussed here.

In the numerical simulation, a cylindrical pipe with a diameter of $140 \mathrm{~mm}$ and height of $1500 \mathrm{~mm}$ is considered. Initially, GHBS particles accumulate at a certain height at the bottom of the pipe with a volume fraction of $\alpha_{s 0}$. The water with the same temperature as that of GHBS occupies the whole pipe at the beginning. Then, warmer water enters the pipe from the bottom with a certain velocity and drags the particles upward. A constant-pressure condition is set at the outlet (Fig. 1b).

To simplify the numerical model and ensure acceptable computation time and errors, the following assumptions are proposed:
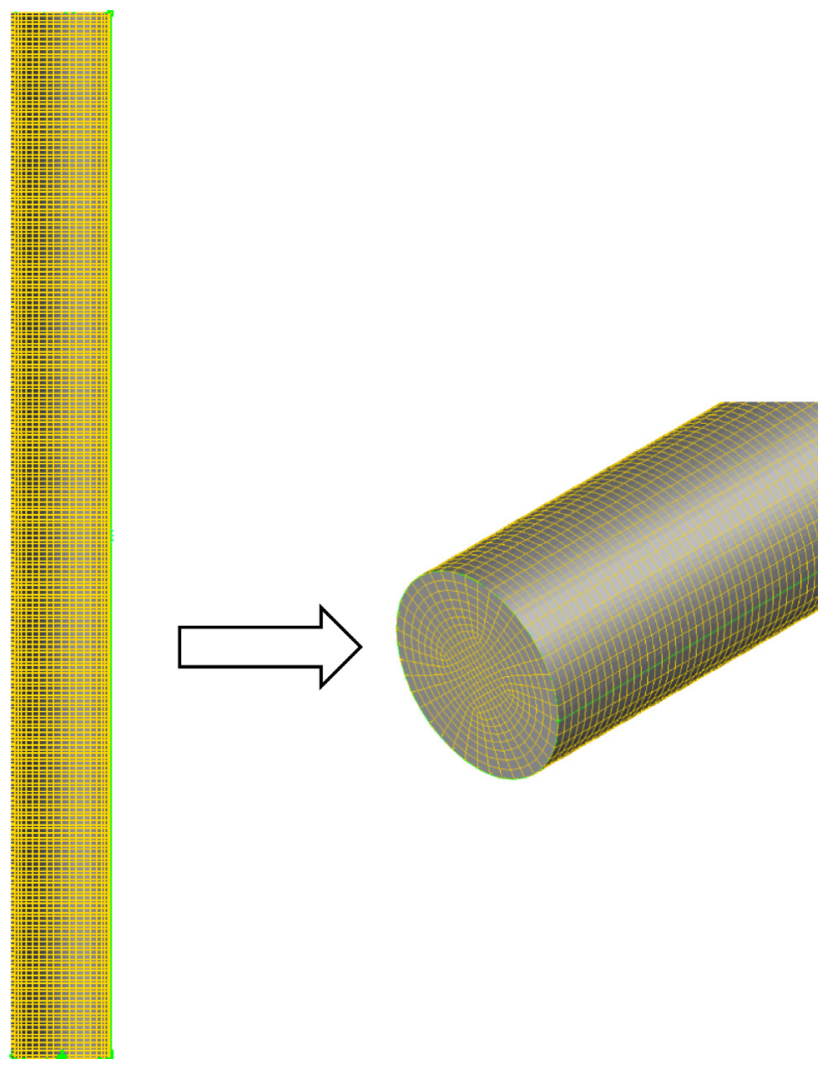

Fig. 4. Structured mesh of the numerical model.

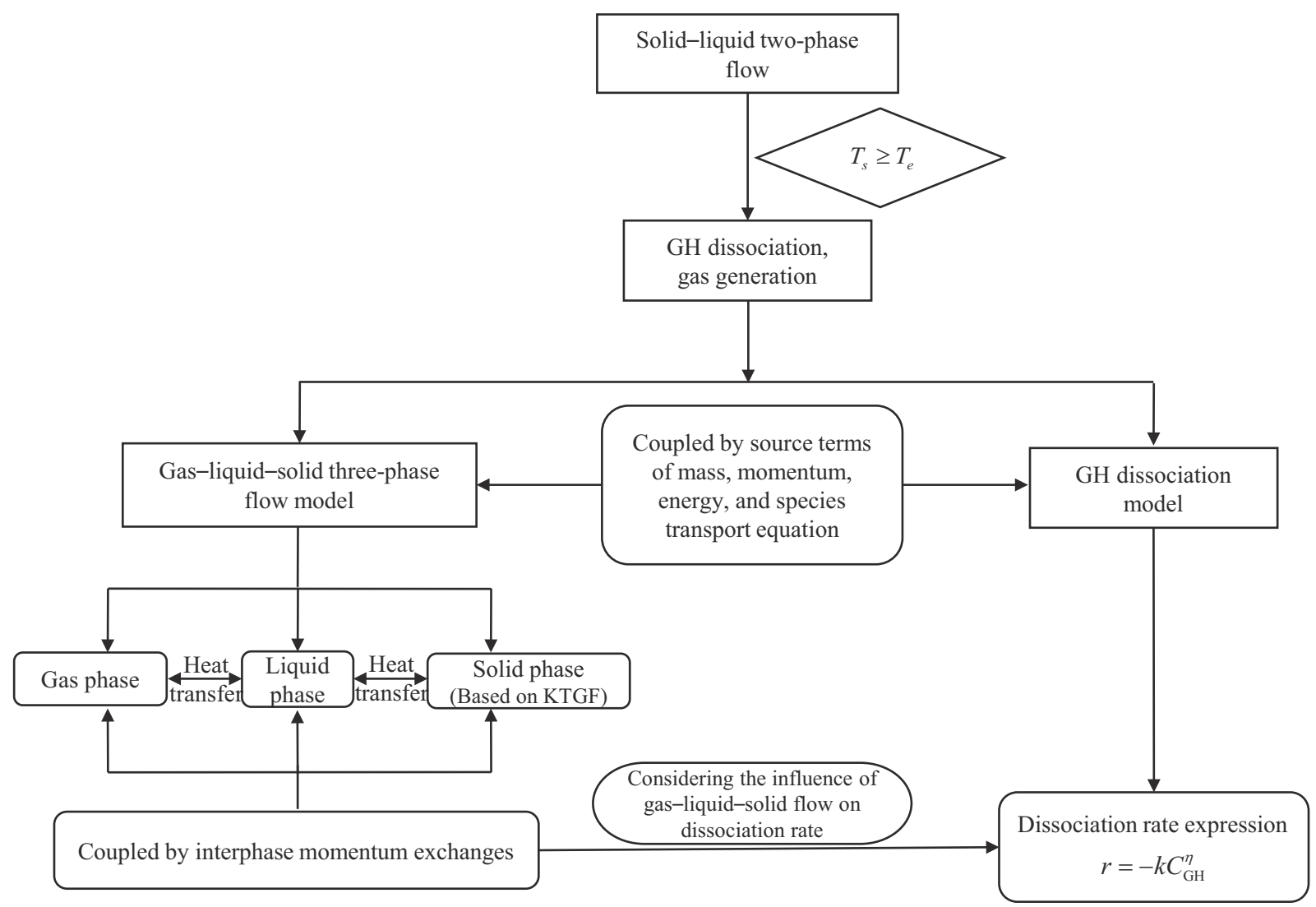

Fig. 3. The numerical simulation process of the multiphase flow transport containing GH dissociation in vertical pipe. 
(i) GHBS particles are assumed to be ideally spherical, and will not collapse during GH dissociation.

(ii) GHBS particles consist of three components, i.e., GH, water, and sand. The thermal conductivity and density of the particles are defined as

$$
R_{s}=\frac{1}{\sum_{i=1}^{3} \frac{Y_{i}}{R_{i}}},
$$

where $Y$ is the mass fraction and $R$ represents the thermal conductivity or density. The subscript $i(=1,2,3)$ indicates $G H$, water, and sand, respectively.
The specific heat of particles is defined as

$$
c_{s}=\alpha_{i} c_{i}
$$

where $\alpha$ is the volume fraction and $c$ represents the specific heat, $\mathrm{J} / \mathrm{kg} \cdot \mathrm{K}$.

(iii) The thermal properties of water, sand, $\mathrm{GH}$, and gas are assumed to be constant because the effects of temperature variation are slight. The gas bubbles keep a uniform and constant diameter because the pressure variation is negligible relative to the water pressure at the outlet. The dissolu-

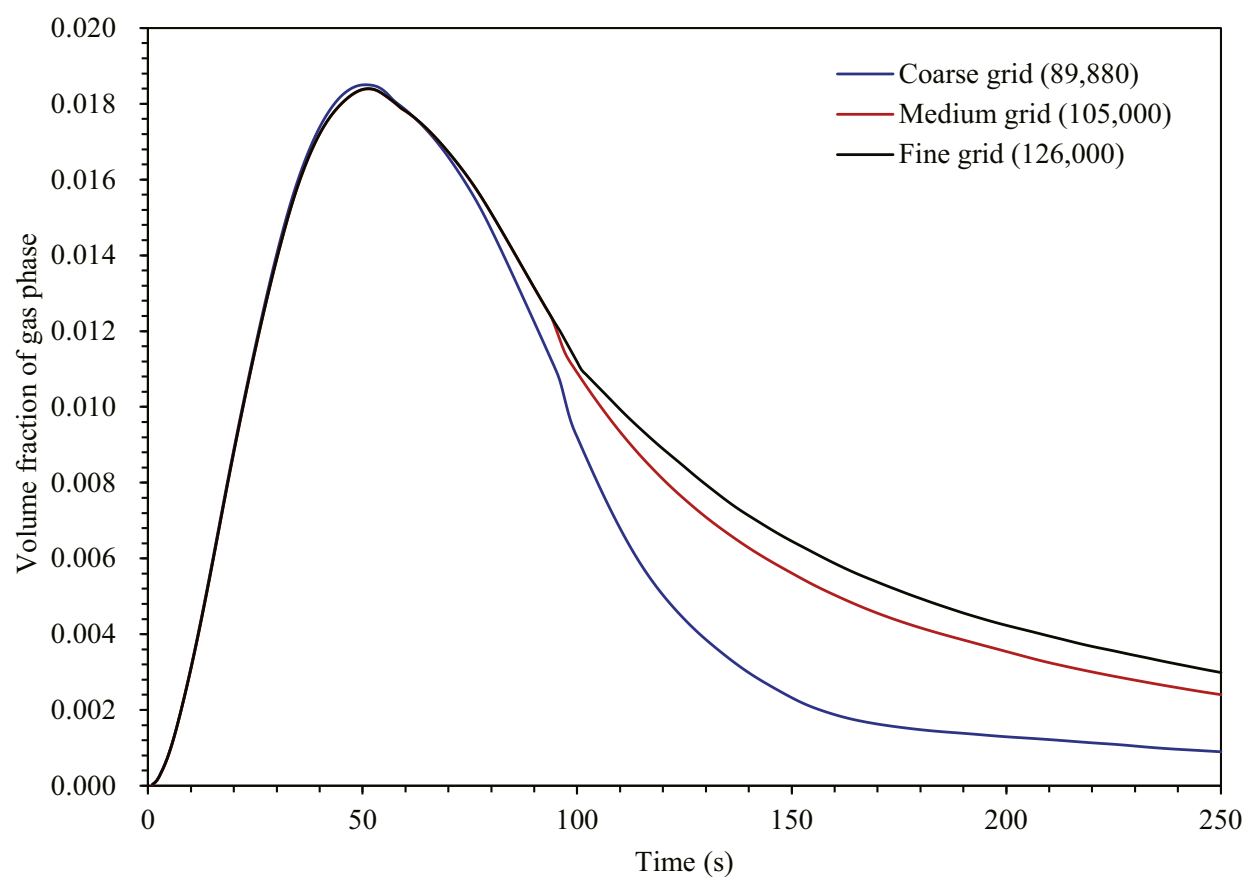

Fig. 5. Comparisons of the gas volume fraction in the pipe with time for different mesh resolutions.

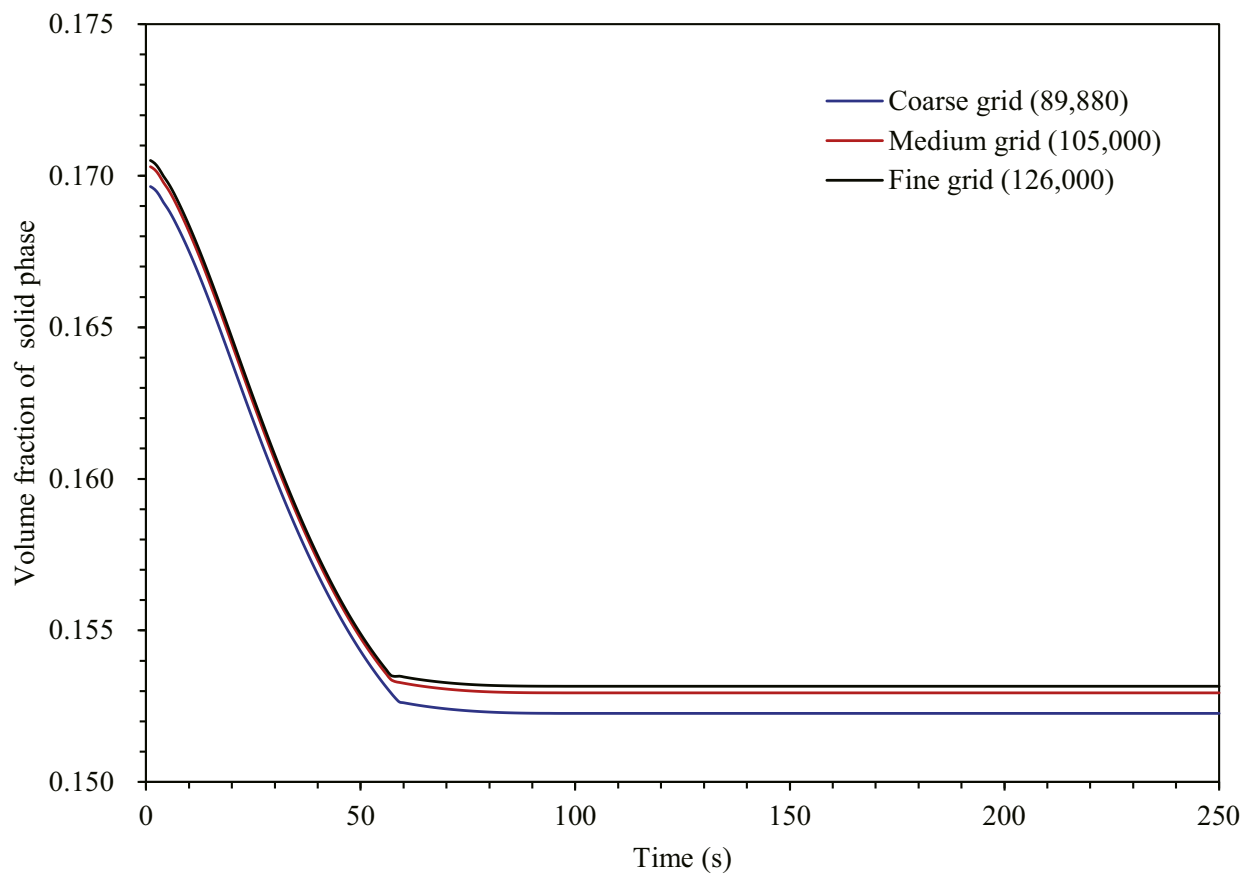

Fig. 6. Comparisons of the solid volume fraction in the pipe with time for different mesh resolutions. 
tion, coalescence, and breakup of the bubbles during the flow process are ignored for simplification.

(iv) The walls are assumed to be insulated. The gas phase comes from GH dissociation, and the heat transfer between the gas and solid phases is ignored.

\subsection{Equations of gas-liquid-solid flow}

In order to describe the transient characteristics of the gas-liquid-solid flow in the vertical pipe, a transient Eulerian three-fluid model within the framework of FLUENT 16.2 is adopted. All three phases are treated as interpenetrating continua. The kinetic theory of granular flow (KTGF) is introduced to simulate the effects of collision and friction among particles. The $\mathrm{GH}$ dissociation is regarded as source terms in the mass, momentum, and energy conservation equations (Liu et al., 2013). The pressure field of each phase is proportional to the phase volume fraction (Panneerselvam et al., 2009).

Here, the gas, liquid, and solid phases represent methane gas, water, and GHBS particles, respectively. The volume fraction is introduced to describe the multiphase flow as interpenetrating continua based on the Eulerian approach.

The volume fraction of the three phases satisfies

$\alpha_{g}+\alpha_{l}+\alpha_{s}=1$.

The volume $V_{q}$ of each phase is defined by (Cornejo and Farías, 2011)

$V_{q}=\int_{V} \alpha_{q} d V$

where $q$ represents gas $g$, liquid $l$, or solid $s$, respectively.

Table 4

Parameters of the numerical model.

\begin{tabular}{lll}
\hline Parameter & Units & Value \\
\hline Pipeline diameter $D$ & $\mathrm{~mm}$ & 140 \\
Pipeline height $H$ & $\mathrm{~mm}$ & 1500 \\
Initial height of particles $h_{0}$ & $\mathrm{~mm}$ & 450 \\
Initial solid volume fraction $\alpha_{s 0}$ & dimensionless & 0.562 \\
Inlet liquid velocity $v_{l 0}$ & $\mathrm{~m} / \mathrm{s}$ & 0.07 \\
Inlet liquid temperature $T_{l 0}$ & $\mathrm{~K}$ & 295.15 \\
Initial solid temperature $T_{s 0}$ & $\mathrm{~K}$ & 280.15 \\
Hydrate phase equilibrium temperature $T_{e}$ & $\mathrm{~K}$ & 285.15 \\
Initial gas temperature $T_{g 0}$ & $\mathrm{~K}$ & 285.15 \\
Inlet granular temperature $\Theta_{s 0}$ & $\mathrm{~m}^{2} / \mathrm{s}^{2}$ & $10^{-5}$ \\
Initial mass fraction of hydrate and water $Y_{i}$ & dimensionless & $0.07,0.12$ \\
Particle-wall restitution coefficient $e_{w s}$ & dimensionless & 0.9 \\
Particle-particle restitution coefficient $e_{s s}$ & dimensionless & 0.9 \\
Specularity coefficient $\delta$ & dimensionless & 0.01 \\
Maximum packing limit $\alpha_{s, \text { max }}$ & dimensionless & 0.6 \\
Angle of internal friction $\varphi$ & rad & $\pi / 6$ \\
Outlet pressure $P_{\text {out }}$ & MPa & 10 \\
\hline & & \\
\hline
\end{tabular}

A summary of the governing equations and constitutive equations is listed in Table 2. Modeling of the multiphase turbulent flow is complex and computationally expensive considering the effects of the secondary phases on the turbulence of the primary phase (Murthy et al., 2007). Hence, the turbulence in the multiphase flow is restricted to the primary phase (Wang et al., 2009). The standard $\kappa-\varepsilon$ dispersed turbulence model is adopted to describe the turbulent motion of the liquid phase.

The interaction forces between different phases include drag force, added mass force, Basset force, and lift forces, including Magnus force and Saffman force. In general, the drag force is always predominant and other forces are much smaller than the drag force (Pan et al., 2016). The added mass force can be present only when high-frequency fluctuations of the slip velocity occur (Rafique et al., 2004). Basset force is important only in the initial period of acceleration and Saffman force is only significant in areas with large velocity gradients, such as near the wall (Liu, 1993). Magnus force can be omitted unless the rotation of the particles is strong (Liu, 1993; Sokolichin et al., 2004). Hence, in this paper, only the drag force is considered for the interphase momentum exchange in the simulation.

\subsection{GH dissociation model}

During the process of hydraulic lifting in the pipe, as the temperature increases and the pressure drops, the $\mathrm{GH}$ in particles dissociates. Accordingly, a large number of bubbles are released into water, and the remaining soil particles continue to move with gas and water flow. In addition, the continuously changing concentration and velocity of the particles in multiphase flow have significant effects on the dissociation rate. The chemical reaction equation of $\mathrm{GH}$ dissociation can be expressed as

$\mathrm{CH}_{4} \cdot 5.75 \mathrm{H}_{2} \mathrm{O}(s) \stackrel{r}{\rightarrow} \mathrm{CH}_{4}(g)+5.75 \mathrm{H}_{2} \mathrm{O}(l)$,

where the heat of dissociation per mole hydrate $\Delta H_{\text {dis }}$ is given by Rueff et al. (1988), $\Delta H_{\text {dis }}=54.5 \mathrm{~kJ} / \mathrm{mol}$.

To describe the GHBS particle dissociation under multiphase flow, the GH dissociation rate is assumed to be proportional to the residual hydrate concentration, and the $\mathrm{GH}$ dissociation rate expression is described as (Li et al., 2018)

$r=\frac{d C_{\mathrm{GH}}}{d t}=-k C_{\mathrm{GH}}^{\eta}$

where $r$ is the reaction rate of $\mathrm{GH}$ dissociation, $\mathrm{kmol} / \mathrm{m}^{3} \cdot \mathrm{s} . C_{\mathrm{GH}}$ is the volumetric molar concentration of non-dissociated $\mathrm{GH}$, $\mathrm{kmol} / \mathrm{m}^{3} . \eta$ is the rate exponent, dimensionless. $C_{\mathrm{GH}}$ is expressed as

$C_{\mathrm{GH}}=\frac{\rho_{\mathrm{GH}} \phi S_{\mathrm{H}} \alpha_{s}}{M_{\mathrm{GH}}}$,

$\rho_{\mathrm{GH}}$ is the density of GH. $\phi$ is the porosity of the particles. $S_{\mathrm{H}}$ is the hydrate saturation in particles. $M_{\mathrm{GH}}$ represents the molar mass of

Table 5

Properties of gas, liquid, and solid phases.

\begin{tabular}{|c|c|c|c|c|c|c|c|}
\hline Phase & & Density $\left(\mathrm{kg} / \mathrm{m}^{3}\right)$ & Diameter (mm) & Viscosity (Pa.s) & Molar mass $(\mathrm{kg} / \mathrm{kmol})$ & Specific heat $(\mathrm{J} / \mathrm{kg} \cdot \mathrm{K})$ & Thermal conductivity $(\mathrm{W} / \mathrm{m} \cdot \mathrm{K})$ \\
\hline \multirow[t]{3}{*}{ Solid } & Sand $^{a}$ & 2720 & 3 & - & 60 & 840 & 3 \\
\hline & Hydrate $^{\mathrm{b}}$ & 920 & & - & 119.5 & 2010 & 0.4 \\
\hline & Water $^{\mathrm{C}}$ & 1003.3 & & 0.001 & 18 & 4155 & 0.6 \\
\hline Liquid & Water $^{\mathrm{c}}$ & 1003.3 & - & 0.001 & 18 & 4155 & 0.6 \\
\hline Gas & Methane $^{\mathrm{d}}$ & 79.68 & 0.3 & $1.4 \mathrm{e}-05$ & 16 & 3099 & 0.04 \\
\hline
\end{tabular}

a Values are quoted from Bai et al., 2007.

b Values are quoted from Sean et al., 2007.

c Values are quoted from Wagner and Pruss, 2002.

d Values are quoted from Friend et al., 1989. 
$\mathrm{GH}, \mathrm{kg} / \mathrm{kmol} . \mathrm{k}$ is the rate constant, and an Arrhenius-type equation is presented:

$k=\frac{A}{\left(\pi d_{s}^{3} / 6\right)^{1-\eta}}\left(\frac{T_{s}}{T_{e}}\right)^{\beta} \exp \left(-\frac{E_{a}}{R T_{s}}\right)$

where $A$ is the pre-exponential factor, $\mathrm{kmol}^{1-\eta} \cdot \mathrm{s}^{-1} \cdot \beta$ is the temperature exponent, dimensionless. $E_{a}$ is the activation energy, $\mathrm{J} / \mathrm{mol}$. $R$ is the universal gas constant, $\mathrm{J} / \mathrm{mol} \cdot \mathrm{K} . T_{e}$ is the $\mathrm{GH}$ phase equilibrium temperature, $\mathrm{K} . T_{e}$ is obtained by the phase equilibrium condition of methane hydrate, proposed by Dickens and Quinby (1994):

$\frac{1}{T_{e}}=3.79 \times 10^{-3}-2.83 \times 10^{-4} \log P_{e}$,

where $P_{e}$ is the equilibrium pressure, MPa.

The kinetic parameters of GH dissociation used in this study are listed in Table 3 . The pre-exponential factor and the activation energy are set as $3.89 \times 10^{12} \mathrm{kmol}^{1-\eta} \cdot \mathrm{s}^{-1}$ and $9.83 \times 10^{4} \mathrm{~J} / \mathrm{mol}$, respectively (Sean et al., 2007). Sean et al. (2007) conducted dissociation experiments of pure methane hydrate balls under water flow conditions and measured the dissociation rate. Consequently, the kinetic data are not suitable for the GHBS particles used in this study, and hence it is necessary to use $\eta$ and $\beta$ to adjust the reaction rates. It is noted that the values of the rate exponent and temperature exponent are set as 0.6 and 2, respectively, to describe the effects of concentration and ambient temperature on the reaction rates.

Few experimental data of the GHBS particles dissociation in the pipe flow are presented in the literature. Li et al. (2016) conducted several trial observational tests to obtain information on the dissociation process of GHBS particles under water-heating condition. Detailed descriptions of the experiments can be found in the literature. Fig. 2 shows the comparison between the dissociation completion time estimated by the $\mathrm{GH}$ dissociation model and the experimental data by Li et al. (2016) at various hydrate saturations.
The experimental conditions were chosen as: environmental pressure $P=0.1 \mathrm{MPa}$, average diameter of particles $d_{s}=2 \mathrm{~cm}$, water temperature $T_{l}=303.15 \mathrm{~K}$, porosity of the particle $\phi=0.4$. The particle volume fraction $\alpha_{s}$ may be different under different saturation conditions in the experiment, so the predicted completion durations by the dissociation model were calculated at different volume fractions. It can be seen that the dissociation completion duration estimated by the dissociation model has the same order of magnitude as that by the experiments. The results are in good agreement with the experimental results for $S_{\mathrm{H}}=2 \%$ and $18 \%$ when $\alpha_{s}=0.2$ with an error less than $11 \%$, and for $S_{H}=11 \%$ when

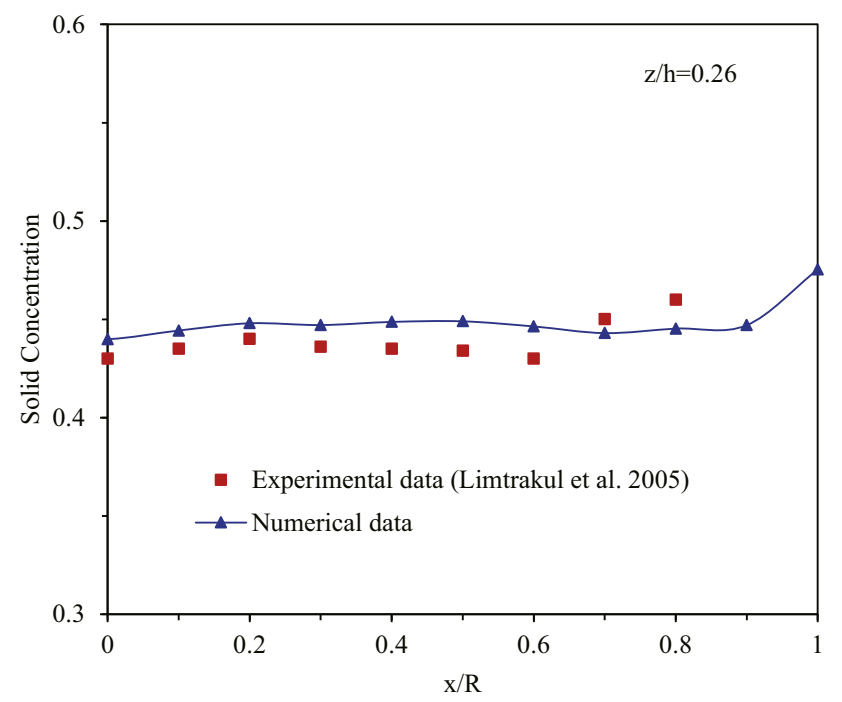

Fig. 8. Simulated and measured solid concentration profiles versus the radial distance in the solid-liquid flow.

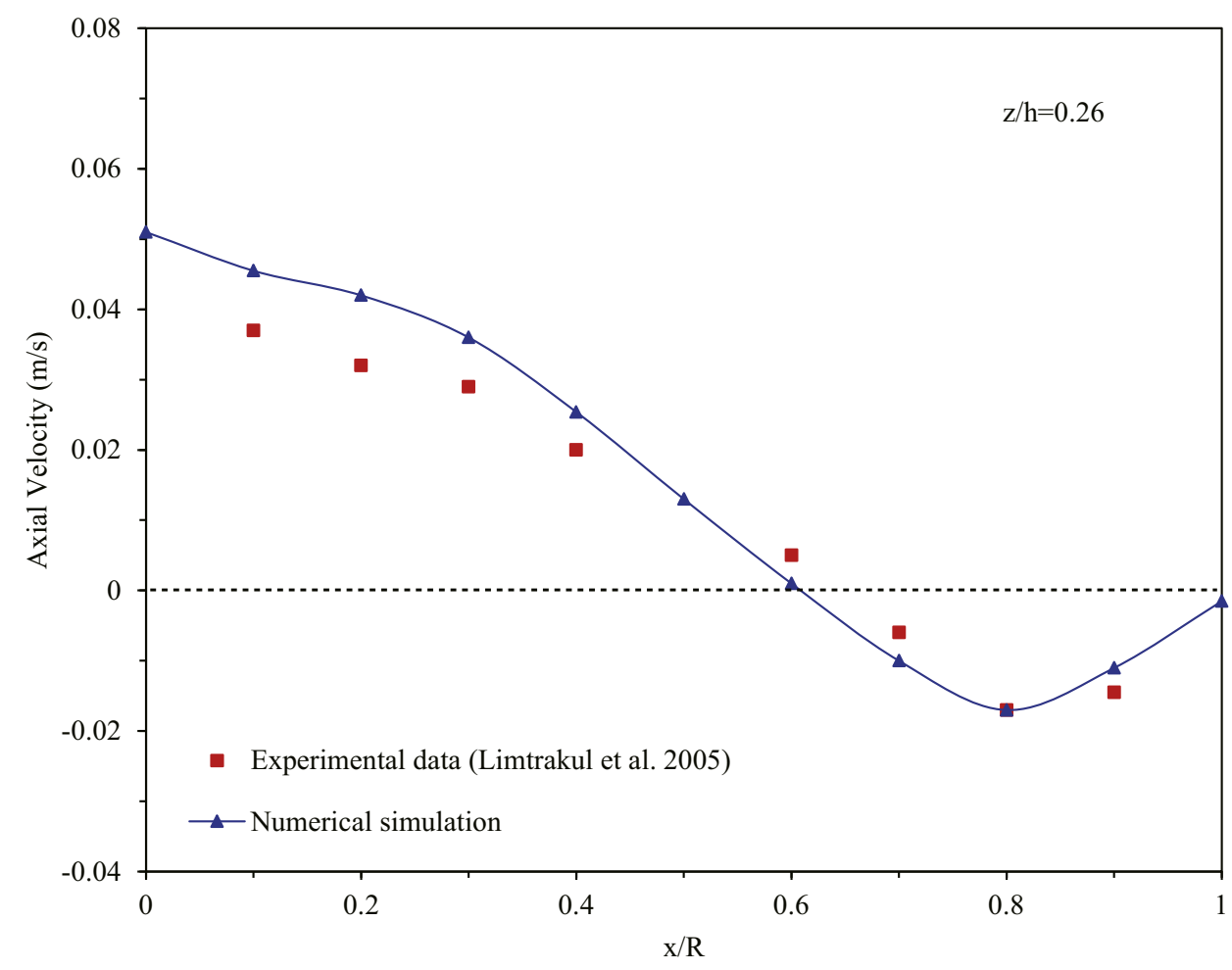

Fig. 7. Simulated and measured axial velocity profiles of particles versus the radial distance in the solid-liquid flow. 
$\alpha_{s}=0.6$ with an error 5.3\%. The dissociation model can describe the main dissociation characteristics of the small GHBS particles under water-heating condition. Considering the complexity of small GHBS particle dissociation under multiphase flow, more indepth theoretical and experimental research is required to understand the dissociation rate. In addition, if the more precise kinetic parameters for the $\mathrm{GH}$ dissociation under multiphase flow are available in the future, they will certainly be used to improve the accuracy of the dissociation model.

\subsection{Species transport equations}

In the Eulerian multiphase flow model, source terms of GH dissociation are introduced in the conservation equations of gas, liquid and solid phases, describing the conservative exchange of mass, momentum, and energy between the phases. Moreover, the change in particle mass would effect the variation in local mass fraction, which is described by particle species conservation equations. The coupling of GHBS particle dissociation and gas-liquid-

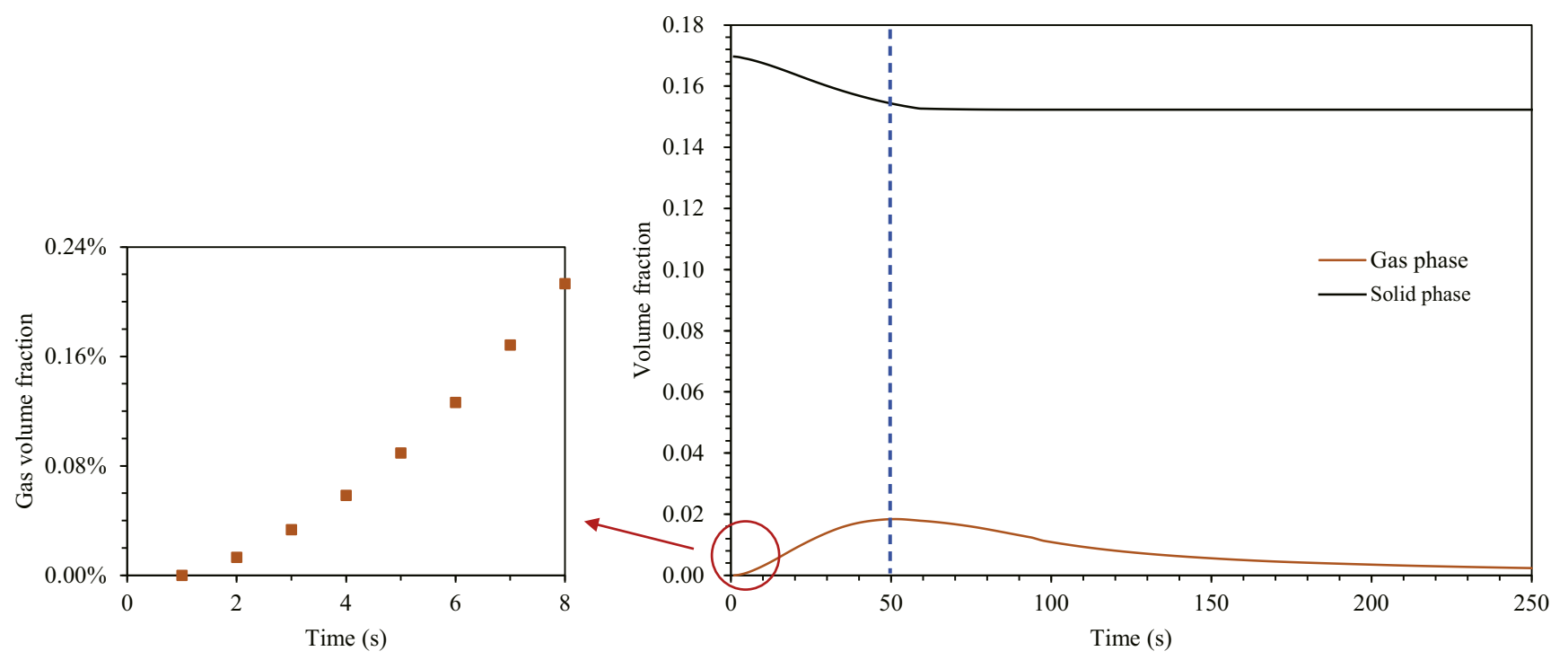

Fig. 9. The simulated volume fraction of the gas and solid phase with time in the pipe.

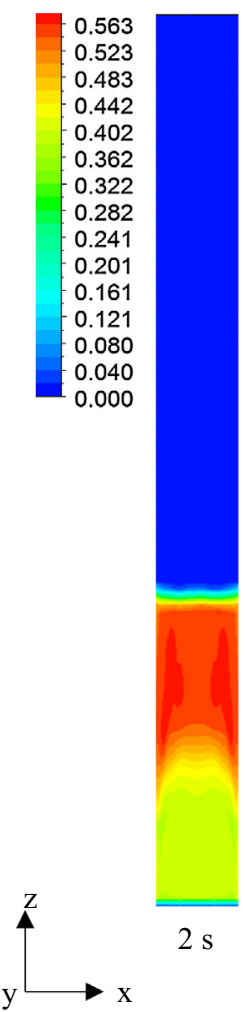

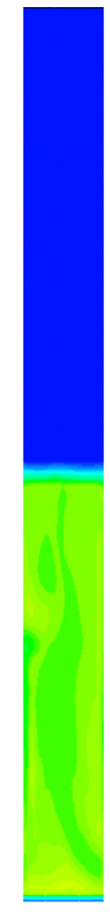

$30 \mathrm{~s}$

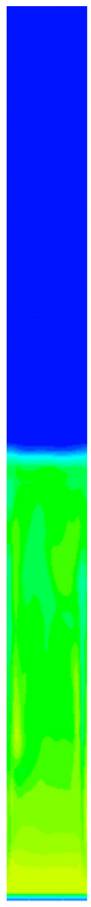

$50 \mathrm{~s}$

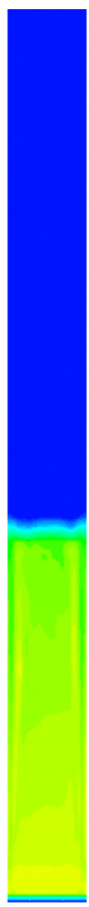

$100 \mathrm{~s}$

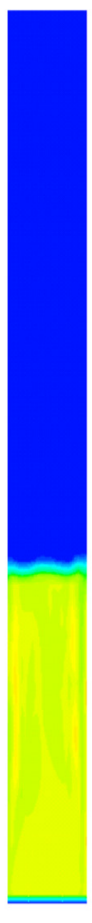

$200 \mathrm{~s}$

(a)

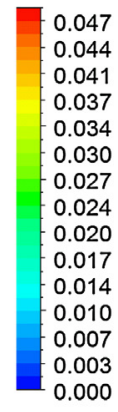

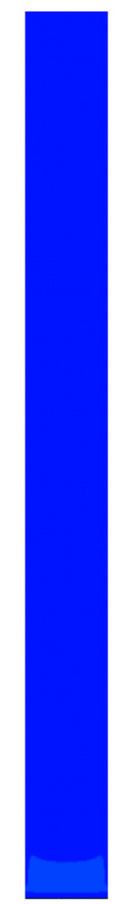

$2 \mathrm{~s}$

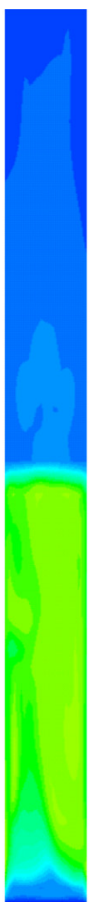

$30 \mathrm{~s}$

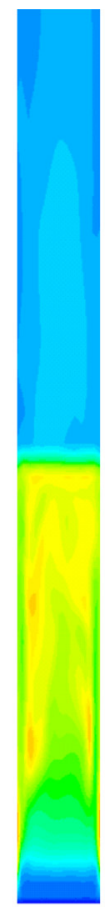

$50 \mathrm{~s}$

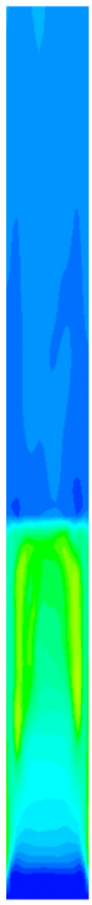

$100 \mathrm{~s}$

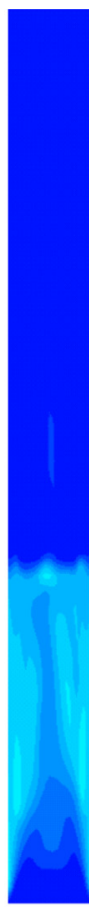

$200 \mathrm{~s}$ (b)

Fig. 10. Instantaneous distribution of the (a) solid and the (b) gas volume fraction for gas-liquid-solid three-phase flow with GH dissociation. 
solid multiphase flow is dependent on these source terms (Zhong et al., 2016). Fig. 3 shows the method of coupling of gas-liquidsolid multiphase flow with $\mathrm{GH}$ dissociation.

The solid particle is a mixture of $\mathrm{GH}$, water, and sand. Here, the change in the properties of GHBS particles is caused by GH dissociation. The species conservation equations for each species can be written as (ANSYS Inc., 2015,)

$\frac{\partial}{\partial t}\left(\alpha_{s} \rho_{s} Y_{i, s}\right)+\nabla \cdot\left(\alpha_{s} \rho_{s} \boldsymbol{v}_{s} Y_{i, s}\right)=S_{i, s}$

where $Y_{i}$ is the local mass fraction of each species. $S_{i}$ is the mass source term due to hydrate dissociation.

The mass source term of $\mathrm{GH}$ is defined by

$S_{\mathrm{GH}}=-M_{\mathrm{GH}} k C_{\mathrm{GH}}^{\eta}$.

The mass source terms of Eqs. (5)-(7) are defined by

$S_{g s}=M_{\mathrm{CH}_{4}} k C_{\mathrm{GH}}^{\eta}$,

$S_{l s}=5.75 M_{\mathrm{H}_{2} \mathrm{O}} k C_{\mathrm{GH}}^{\eta}$,

where $M_{\mathrm{CH}_{4}}$ and $M_{\mathrm{H}_{2} \mathrm{O}}$ are the molar mass of gas and water, respectively.

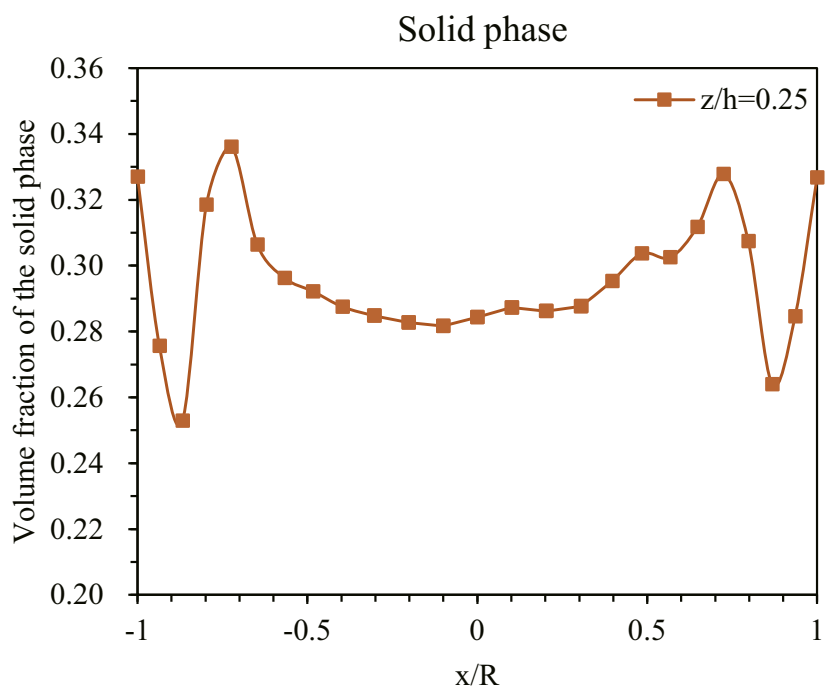

(a) $\mathrm{t}=50 \mathrm{~s}$

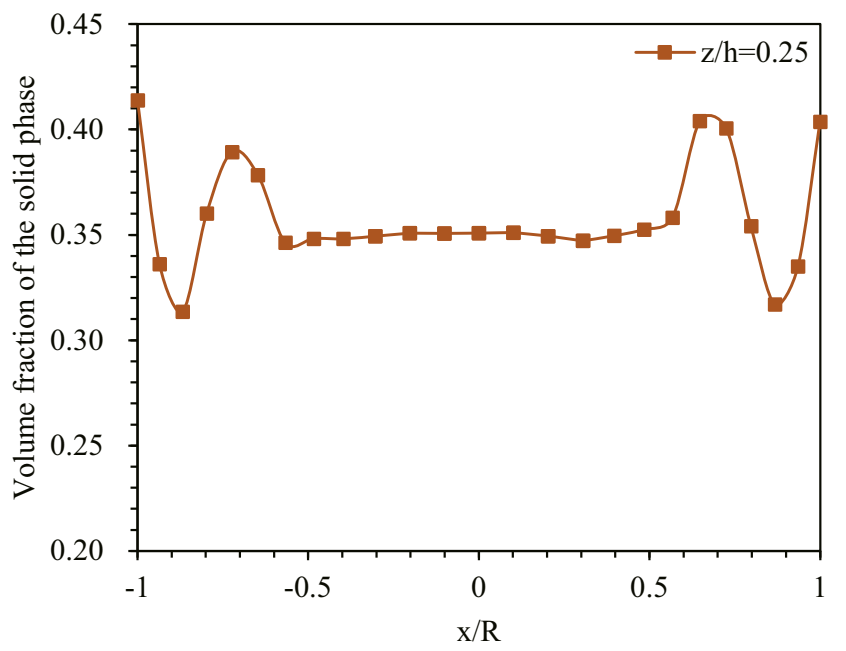

\subsection{Initial and boundary conditions}

Initially, GHBS particles with a certain height were statically located at the bottom of the pipe. At the inlet, a constant liquid velocity was given, and the granular temperature was taken as a small value $10^{-5} \mathrm{~m}^{2} / \mathrm{s}^{2}$ for the convergence of the granular temperature equation. The standard $\kappa-\varepsilon$ model was adopted to describe the inlet turbulence. The following empirical formula was used to calculate the turbulence intensity and scale:

$I=0.16\left(\operatorname{Re}_{D_{\mathrm{H}}}\right)^{-\frac{1}{8}}$,

$l=0.07 L$

where $R e_{D_{\mathrm{H}}}=\rho_{l} v_{l 0} D_{\mathrm{H}} / \mu_{l}$ is the turbulence Reynolds number, dimensionless. $v_{10}$ is the injection velocity of the liquid phase. $D_{\mathrm{H}}$ and $L$ are the hydraulic diameter and characteristic size, respectively, taken as the diameter of the pipe. At the wall, there is no slip for the gas and liquid phase and no normal velocity for the solid phase. The Johnson and Jackson (1987) boundary condition was used for the solid-phase tangential velocity and granular temperature.
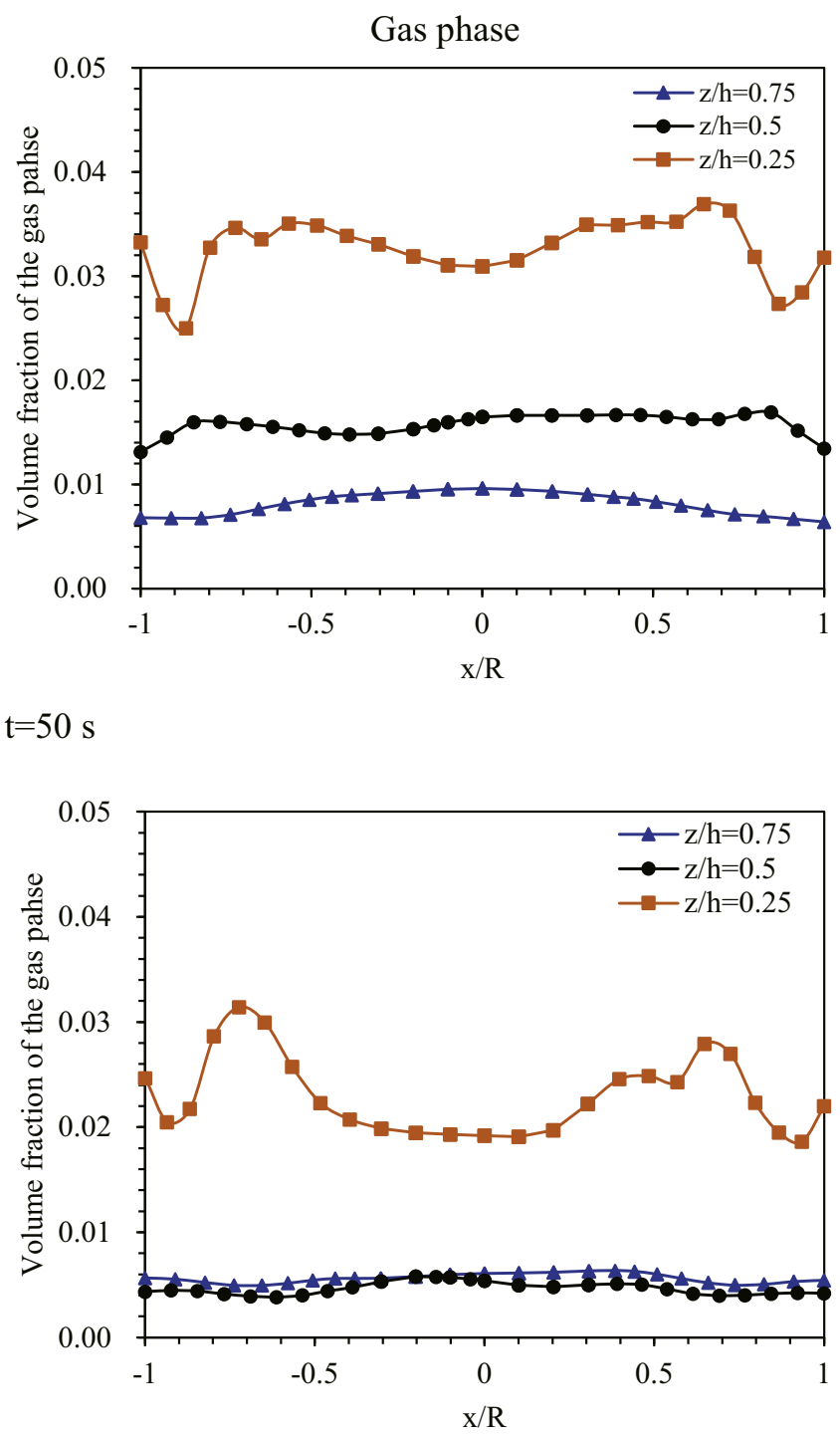

(b) $\mathrm{t}=100 \mathrm{~s}$

Fig. 11. The radial volume fraction profile of the solid and gas at different relative $z / h$ for (a) $t=50 \mathrm{~s}$ and (b) $t=100 \mathrm{~s}$. 
$v_{s t, w}=-\frac{6 \mu_{s} \alpha_{s, \max }}{\pi \delta \rho_{s} \alpha_{s} g_{0, s s} \sqrt{3 \Theta_{s}}} \frac{\partial v_{s t, w}}{\partial n}$,

$\Theta_{w}=-\frac{k_{\Theta_{s}} \Theta_{s}}{e_{w s}} \frac{\partial \Theta_{w}}{\partial n}+\frac{\sqrt{3} \rho_{s} \alpha_{s} v_{s} g_{0 . s s} \Theta_{s}^{3 / 2}}{6 \alpha_{s, \max } e_{w s}}$

where $\delta$ is the specularity coefficient between the particle and the wall, dimensionless. $e_{w s}$ is the particle-wall restitution coefficient, dimensionless.

The pressure was assumed to be $10 \mathrm{MPa}$ at the outlet (assuming seawater with $1000 \mathrm{~m}$ depth pressed the outlet). The numerical simulation in the present work is based on experimental scale; the height of the pipe is $1.5 \mathrm{~m}$, so the pressure difference between the inlet and the outlet is about $0.01 \mathrm{MPa}$. According to Eq. (63), the amplitude of variation of the equilibrium temperature $\Delta T_{e}$ is $0.01 \mathrm{~K}$. The inlet liquid temperature $T_{l 0}$ is taken as $295.15 \mathrm{~K}$, then $\Delta T_{e} / T_{l 0}=3.4 \times 10^{-5} \ll 1$. Therefore, the influence of the pressure
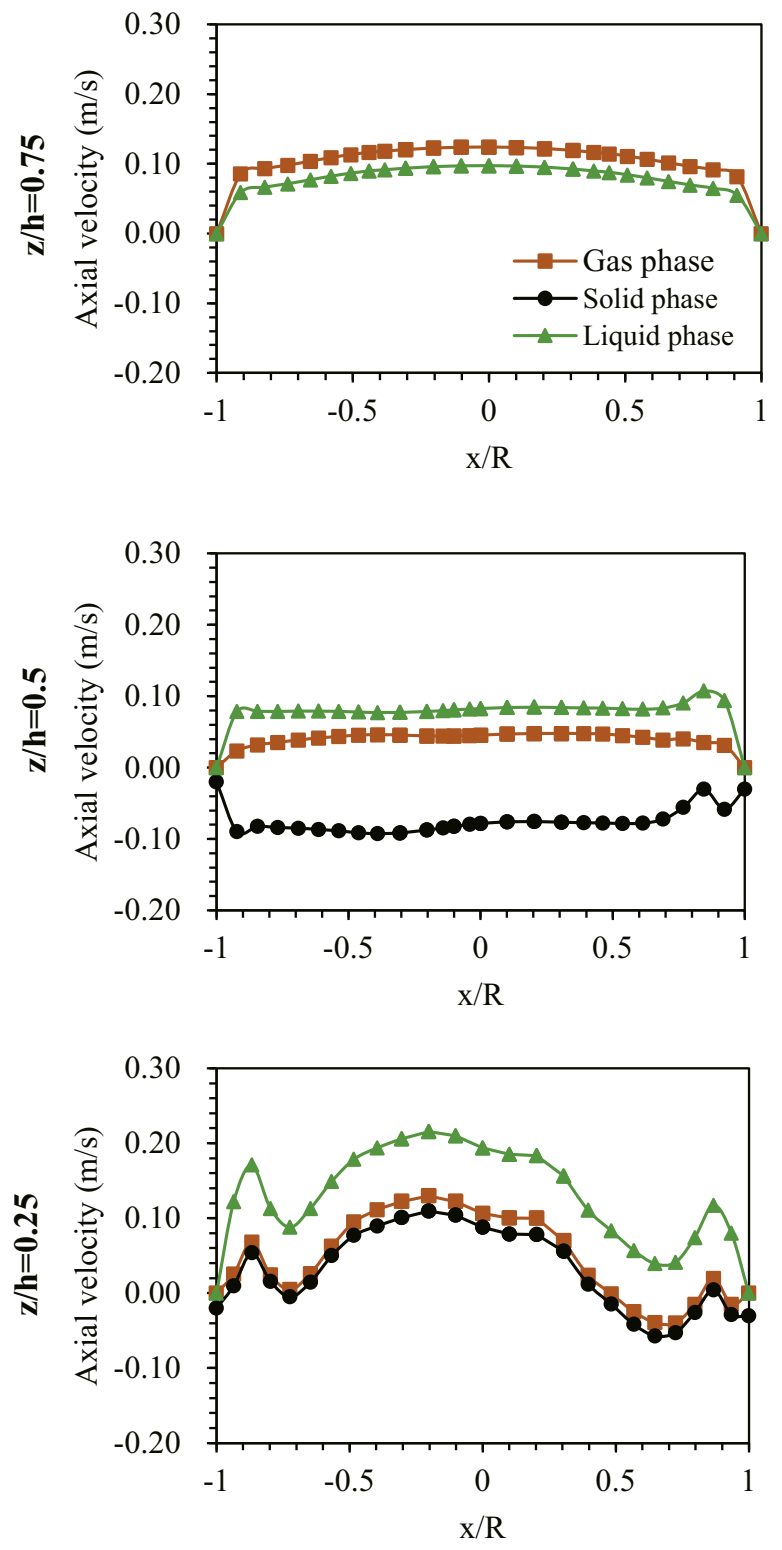

(a) $\mathrm{t}=\mathbf{5 0} \mathrm{s}$ change along the vertical pipe on the GH dissociation rate is not considered in this study. The equilibrium temperature is taken as the temperature corresponding to the outlet pressure (10 $\mathrm{MPa})$, $T_{e}=285.15 \mathrm{~K}$.

\subsection{Numerical method}

The finite-volume method was used to solve the presented mathematical models. The phase-coupled SIMPLE method was used for pressure-velocity coupling. The gradient was discretized with the Green-Gauss cell-based method. A first-order upwind discretization was used to solve the equation of volume fraction, and a second-order upwind discretization was used to solve the equations of mass, momentum, thermal energy, turbulence, species conservation, and granular temperature. The time step was set as $0.001 \mathrm{~s}$, and the maximum number of iterations per time step was set as 50 .
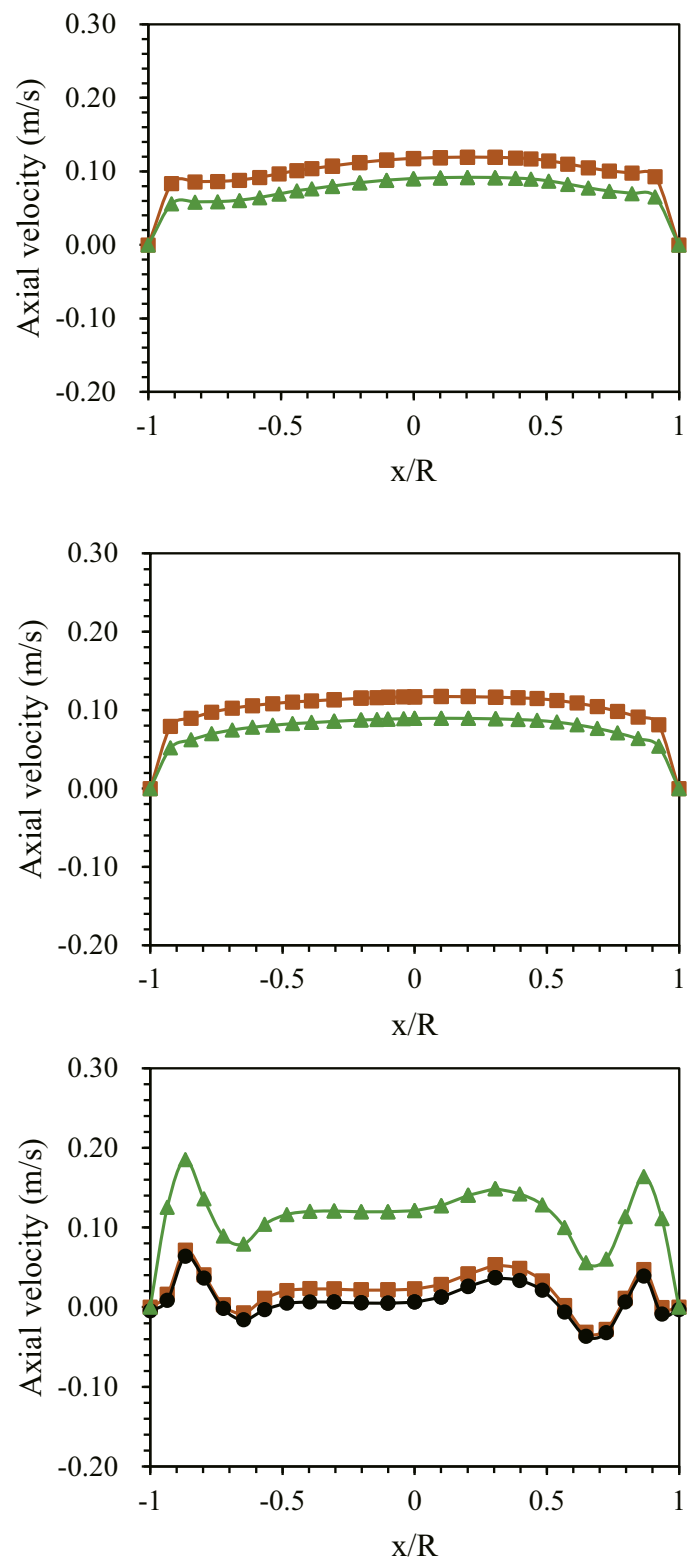

(b) $\mathbf{t}=\mathbf{1 0 0} \mathrm{s}$

Fig. 12. Radial profiles of three phases axial velocity at different relative $z / h$ for $(a) t=50 s$ and $(b) t=100 s$. All graphs share the same legend. 
The numerical mesh is shown in Fig. 4. An O-type structured hexahedral grid was adopted to guarantee the computation accuracy and convergence. The standard wall function proposed by Lanuder and Spalding (1974) was used, and the near-wall cells refinements were adopted to fulfill the requirement of the $\mathrm{y}^{+}$value (taken as 30). Three groups of grid numbers, 89,880, 105,000, and 126,000 (indicating coarse, medium, and fine grids, respectively), were adopted to check the mesh sensitivity. As illustrated in Fig. 5, there is no significant difference in the gas volume fraction with time for the last two grids, whereas they are deviated obviously with that of the coarse grid. The volume fraction of the solid phase with time for different grid resolutions is shown in Fig. 6. The difference from the predicted volume fraction is insignificant for the coarse, medium, and fine grids. Hence, the grid number of 105,000 was selected in the following simulation considering the influences of computation time and accuracy.

\section{Results and discussion}

First, the numerical model is verified by the experimental data of Limtrakul et al. (2005). Second, the main characteristics of the multiphase flow is simulated by using the initial and boundary conditions shown in Table 4 and the properties of the three phases (shown in Table 5). Third, the effects of the dissociation of GHBS particles with various hydrate saturations on pressure gradient, bed expansion, and gas production in the pipe are investigated.

\subsection{Model verification}

Due to the lack of experimental data on the gas-liquid-solid flow containing $\mathrm{GH}$ dissociation in the vertical pipe, the numerical model is verified by comparing the experimental data (Limtrakul et al., 2005) and numerical data of solid-liquid two-phase flow. Other numerical models (Jain et al., 2017; Panneerselvam et al., 2007) also used the same experimental data for verification. Limtrakul et al. (2005) measured the distribution of concentration and velocity in a liquid-solid fluidized bed using gamma-ray-based computer tomography (CT) and computer-aided radioactive particle tracking (CARPT). The parameters and the fluidized bed dimensions used for the simulation are considered the same as those of the experiments (shown in Table 4). The liquid phase is tap water. The solid phase is glass beads with a diameter of $3 \mathrm{~mm}$ and density of $2500 \mathrm{~kg} / \mathrm{m}^{3}$. When the overall average solid concentration remains constant, it is deemed that the steady state of the solidliquid fluidized bed is reached. Then, a further $100 \mathrm{~s}$ is simulated to obtain the time-averaged quantities.

The computed and experimental values of the averaged solid concentration are 0.44 and 0.43 , respectively, with an error less than $3 \%$. Fig. 7 shows the simulated and measured axial velocity profiles of particles in radial direction $390 \mathrm{~mm}$ above the bottom. The simulation captures the main feature of the flow that particles move upwards at the core region and downwards at the wall region; the two results have an error of less than $30 \%$ except for $x / R=0.6$ and $x / R=0.7$. Due to the change in the velocity direction at the transition area, the error between the simulated and measured values reaches $80 \%$ at $x / R=0.6$ and $67 \%$ at $x / R=0.7$. However, the transition point of zero time-averaged axial velocity predicted by the simulation and measured by the experiments occurs between $x / R=0.6$ and 0.7 , and the coefficient of determination between the simulated and measured data is 0.98. Fig. 8 shows the simulated and measured time-averaged solid concentration along the radius $390 \mathrm{~mm}$ above the bottom. The solid concentration increases from the center to the wall but changes little in magnitude. The simulated values are slightly higher at the core region and lower at the wall region than the measured values, with a maximum deviation of less than $4 \%$. The deviation between the simulated and measured results may be caused by the simplification in the system geometry and the choice of the empirical closed equations for the solid phase. The numerical simulation model used in this study is considered to be within the allowable errors.

The movement of the gas bubbles after GH dissociation in the solid-liquid flow is qualitatively similar to the gas-phase flow pattern in a gas-liquid-solid three-phase fluidized bed. The Eulerian three-fluid model has been used to study the gas-liquid-solid flow phenomena (Hamidipour et al., 2012; Murthy et al., 2007;

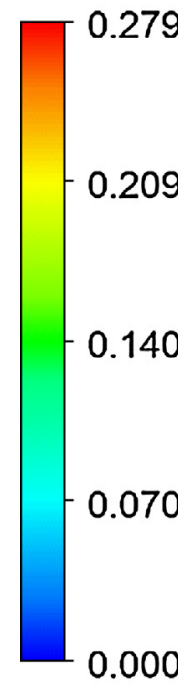

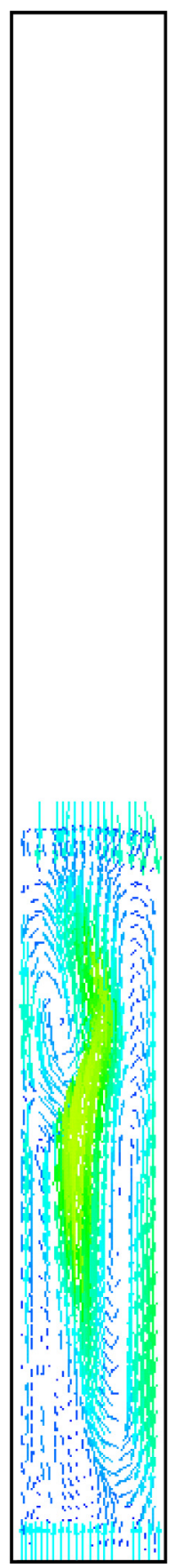

(a)

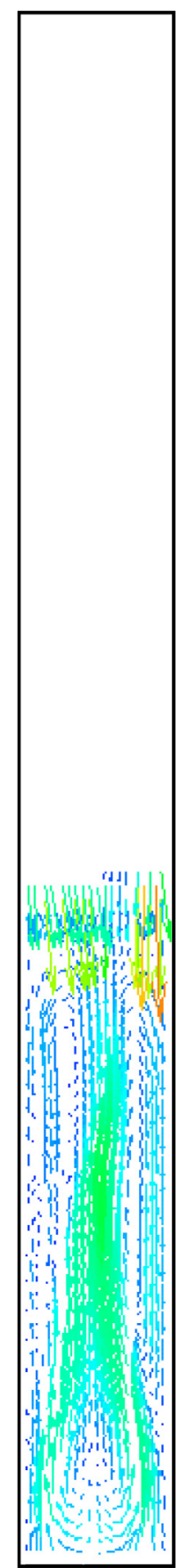

(b)
Fig. 13. Instantaneous snapshots of solid velocity vectors for (a) the gas-liquidsolid three-phase flow with dissociation and (b) the solid-liquid two-phase flow without dissociation at the moment of $30 \mathrm{~s}$. 
Panneerselvam et al., 2009), and the accuracy of the model is verified by the experimental data. Hence, the Eulerian model is applied to describe the gas-liquid-solid three-phase flow with $\mathrm{GH}$ dissociation.

\subsection{Simulation of gas-liquid-solid flow with $\mathrm{GH}$ dissociation in a vertical pipe}

\subsubsection{Flow characteristics}

Initially, the liquid-solid two-phase flow is in a stable state. Owing to the convective heat transfer between the water and the particles in the bottom of the pipe, GHBS dissociates to produce gas bubbles when the solid temperature reaches the phase equilibrium temperature of $\mathrm{GH}$. It is assumed that the initial temperature of methane bubbles released from particles is equivalent to the equilibrium temperature of GH. Fig. 9 shows the changes in the gas and solid volume fraction with time. The dissociation reaction takes place at $t=2 \mathrm{~s}$. The initial liquid-solid two-phase flow transforms into gas-liquid-solid three-phase flow. The gas volume fraction increases gradually while the solid volume fraction decreases gradually. The particles are dragged upwards by the flow of gas bubbles and water, increasing the voidage of the fluidized bed. Fig. 10 shows the instantaneous distribution of the solid and the gas volume fraction during the multiphase flow with GH dissociation. The continuous production of gas bubbles leads to the redistribution of the phase volume fractions, accompanied by the rising of solid particles. Subsequently, the distribution height of the solid phase slowly increases along the pipe. The expansion of the solid reaches the maximum at about $50 \mathrm{~s}$, and then slowly declines with mass gas bubbles rising to the top of the pipe. Fig. 11 shows the radial volume fraction of the gas and solid phase at different bed heights $z / h$ for $t=50 \mathrm{~s}$ and $t=100 \mathrm{~s}$, respectively. In these figures, the dimensionless lateral position $x / R$ is used, where $R$ is the pipe radius. Both the gas and solid phases present a typical core-annular flow along the pipe during GH dissociation at the bottom region: the dilute suspension at the center region and the dense suspension at the wall region. The gas bubbles migrate towards the center at the top region and the distribution of gas volume fraction tends to be uniform in the radial direction. With gas bubbles moving up to the top region, the remaining particles settle down to the bottom of the pipe due to gravity. It is noted that the volume fraction of gas phase is higher at a lower height $(z / h=0.25)$ and lower at a higher height $(z / h=0.75)$. This may be because the gas comes from the particles accumulated at the bottom of the pipe and then moves upward. During the upward migration, the gas is continuously generated at the bottom. Hence, the volume fraction of the gas phase is higher at a lower height.

The radial non-uniform distribution of the solid and gas volume fraction is caused by the non-uniform axial velocity, flowing upwards in the core and downward near the wall at the initial stage of dissociation (Fig. 12a). The velocities of the three phases are close to zero near the wall region due to the constraint of a no-slip boundary and reach the peak value in the core region. The velocity of the liquid is the highest at the bottom region, and the velocity of the solid is the lowest due to the hysteresis effect. It can be also observed that the initial velocity of the gas releasing from the particles has the same distribution trend as the velocity of the solid. Then, the velocity of the gas increases during flow and becomes greater than those of the solid and water at the top region, indicating that the upward flow of the liquid and solid is accelerated by the drag force of the gas. It is assumed that gas bubbles flow upwards with the stream swirl (Wang et al., 2009), leading to more back-mixing and internal circulation behavior (Fig. 13). With the mass production of gas, the peak velocity shifts to the left and right of center due to the influence of the vortex flow. The cross-sectional velocity becomes more homogeneous (Fig. 12b).

Fig. 14 shows that the mass fraction of water and sand increases gradually while the $\mathrm{GH}$ mass fraction decreases during $\mathrm{GH}$ dissociation. The mass fraction of GH is zero at approximately $t=90 \mathrm{~s}$, indicating that the GH dissociation completes. The model can capture the phenomenon of GHBS particles dissociation well.

\subsubsection{Hydrate dissociation rate}

According to Eqs. (60)-(62), the GH dissociation rate mainly depends on the molar concentration of non-dissociated $\mathrm{GH}$ and the GH temperature. The higher slip velocity between the solid

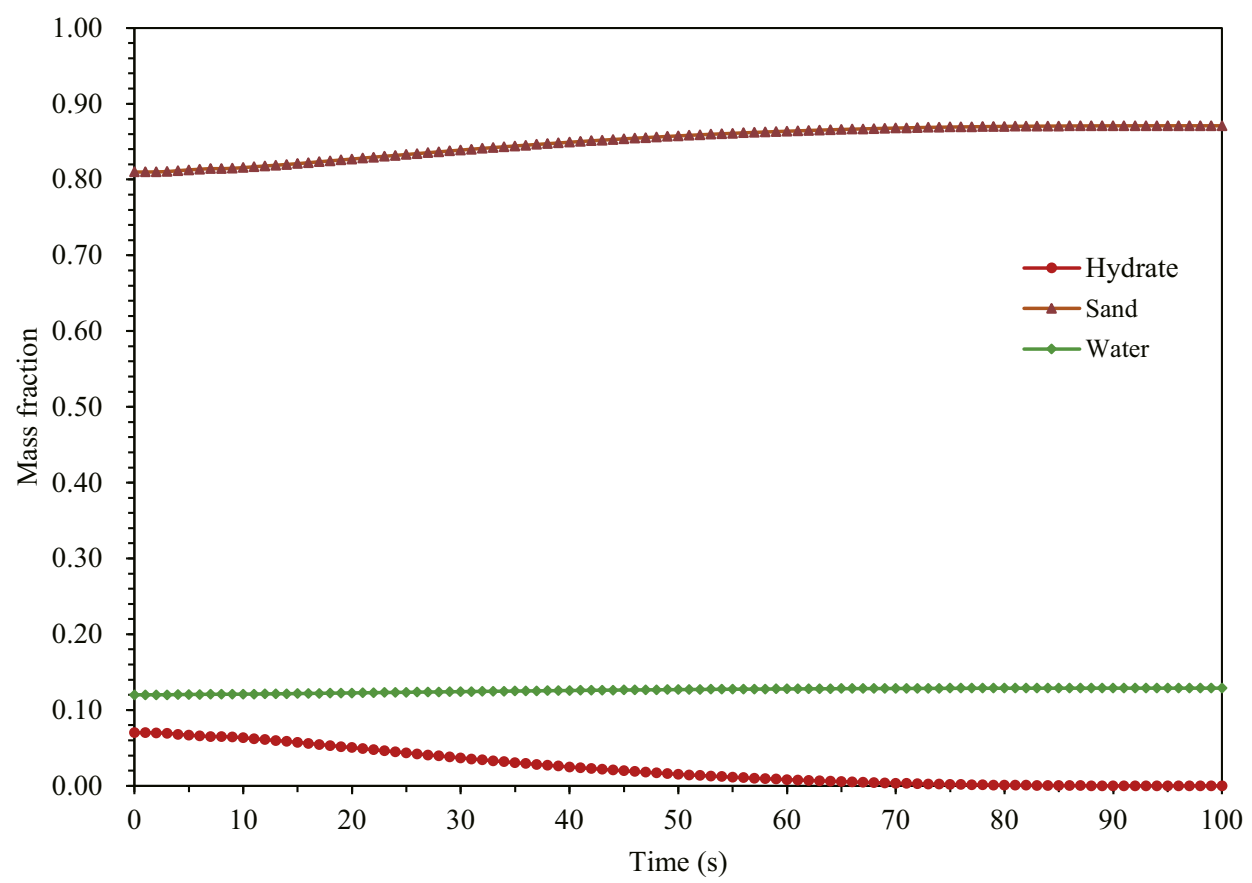

Fig. 14. Comparison of the mass fraction of $\mathrm{GH}$, water, and sand with time in the particles. 
and liquid phases leads to higher convective heat transfer efficiency but lower solid concentration, which in turn affects the GH dissociation rate. Fig. 15 shows the simulated axial $(y=0)$ distribution contours of the GH dissociation rate, solid axial velocity, molar concentration of $\mathrm{GH}$, and solid temperature at $5 \mathrm{~s}$. Higher slip velocity between the solid and liquid phases at the core region leads to the core-annular structure of the concentration and temperature of the solid, smaller in the center region and larger in the near-wall region. $\mathrm{GH}$ dissociation mainly occurs in the region with higher GH molar concentration and temperature. It is demonstrated that the hydrodynamic behaviors affect the $\mathrm{GH}$ dissociation process significantly. The axial distribution of the $\mathrm{GH}$ dissociation rate, solid volume fraction, and temperature of the gas and solid particles at $x / R=0$ for $\mathrm{t}=5 \mathrm{~s}$ is shown in Fig. 16 . The distribution of the dissociation rate and the solid volume fraction follows the same trend along the bed height. It is noted that the dissociation rate increases with the volume fraction of the solid at about $410 \mathrm{~mm}$ above the entrance (Fig. 16a and b). In addition, because $\mathrm{GH}$ dissociation is an endothermic reaction, the progressive dissociation leads to a decrease in the temperature of the gas and solid particles (Fig. 16c and d). Due to the continuous supply of water providing sufficient heat, the temperature of the gas and solid increases dramatically to the water temperature level in the pipe.

\subsubsection{Pressure gradient and bed expansion}

To understand the effects of GH dissociation on pressure gradient in the pipe and bed expansion, solid-liquid two-phase flow without hydrate dissociation was simulated first. After the stable state was reached, GH dissociation was introduced. Fig. 17 shows the variation of the pressure gradient in the entire pipe with time. The pressure gradient along pipe is the sum of frictional and static pressure gradients. The frictional pressure gradient is the energy loss caused by the interaction between three phases, whereas the static pressure gradient is caused by the changes in the static head of the gas phase. It can be observed that the pressure gradient is generally stable at a constant value for the solid-liquid twophase flow during $t_{1}=0 \mathrm{~s}$ to $t_{2}=15 \mathrm{~s}$. When $\mathrm{GH}$ dissociation starts at $15 \mathrm{~s}$, the pressure gradient begins to fluctuate violently as the gas volume continues to grow. The minimum peak value is much smaller than the pressure gradient of the solid-liquid two-phase flow for most of the time. In other words, a smaller inlet water velocity is sufficient to lift the same solid particles for the gas-liquid-solid flow with GH dissociation as that of the solid-liquid flow. The GH dissociation phenomenon is beneficial to hydraulic transport, elevation of water and particles, and reducing the power of the transportation system. With the decrease in GH saturation, the degree of pressure gradient fluctuation decreases gradually until it disappears at the moment of $72 \mathrm{~s}$. At approximately

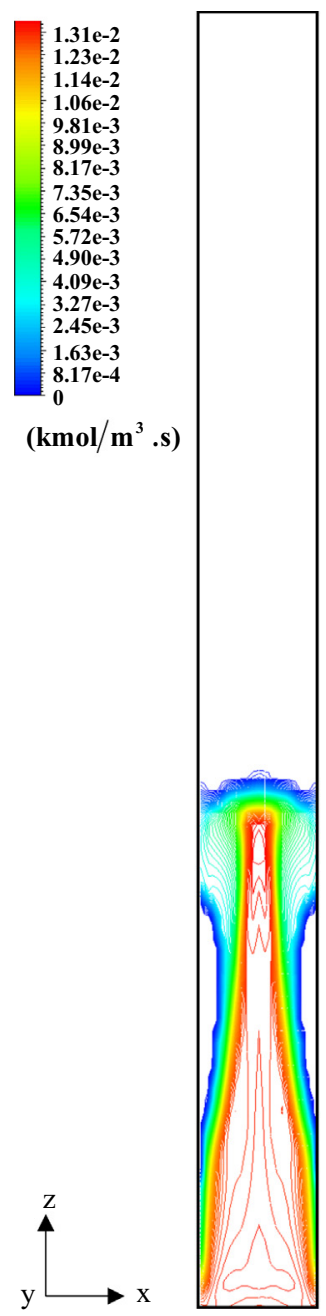

(a)
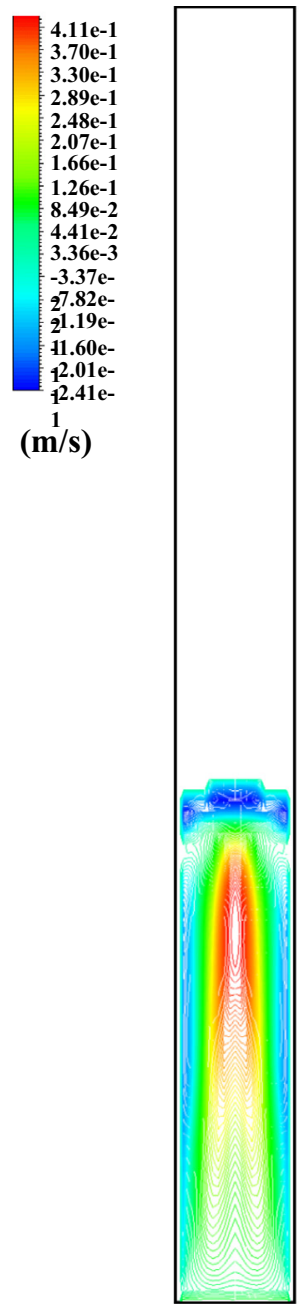

(b)

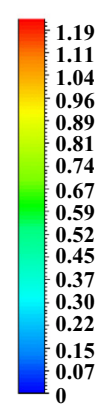

$\left(\mathrm{kmol} / \mathrm{m}^{3}\right)$

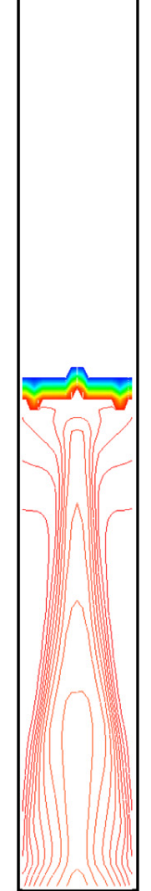

(c)

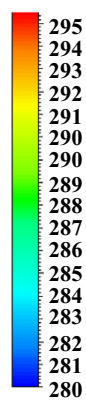

(K)

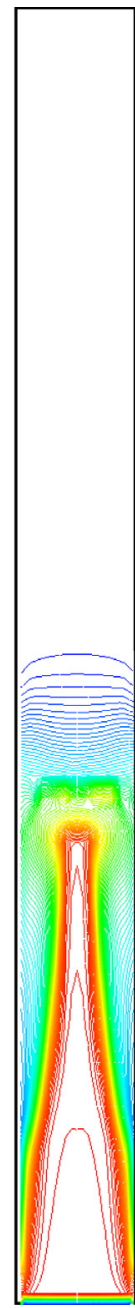

(d)

Fig. 15. Relationships among (a) hydrate dissociation rate, (b) solid axial velocity, (c) molar concentration of hydrate, and (d) solid temperature in the pipe at 5 s. 


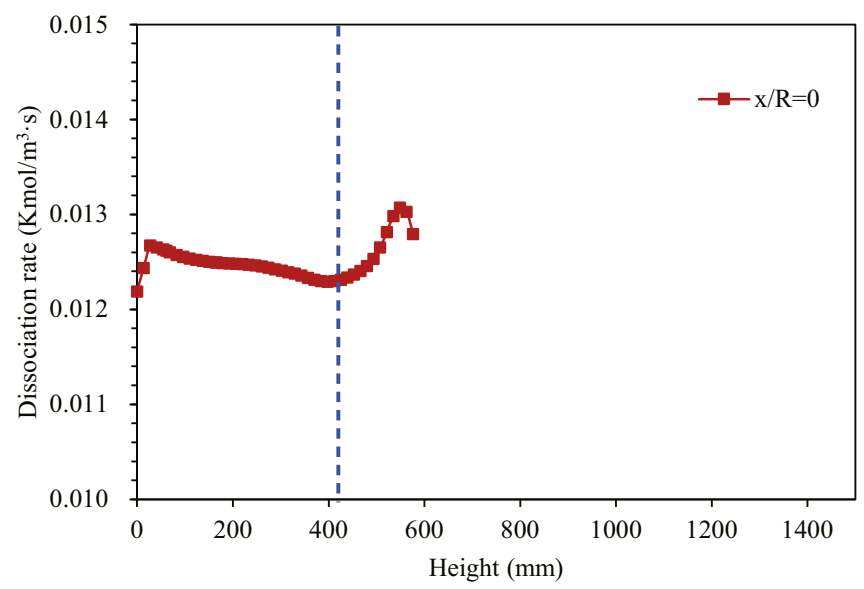

(a)

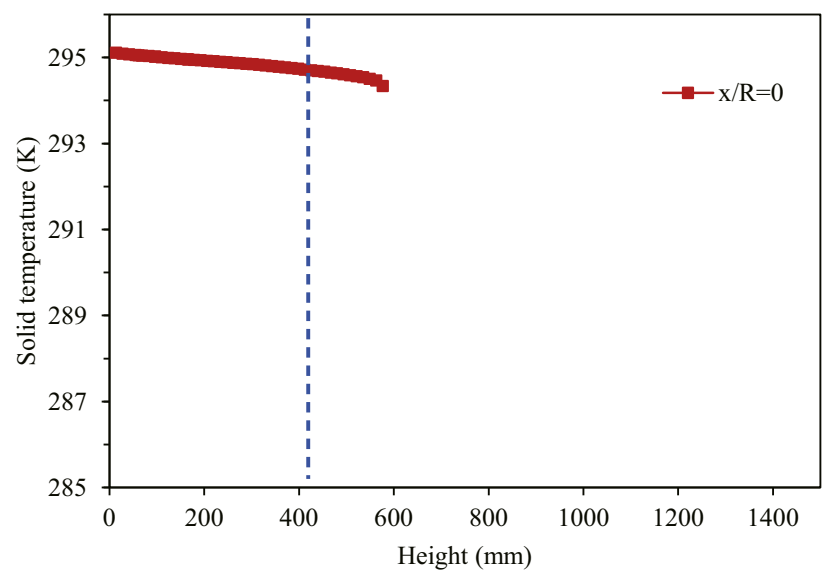

(c)

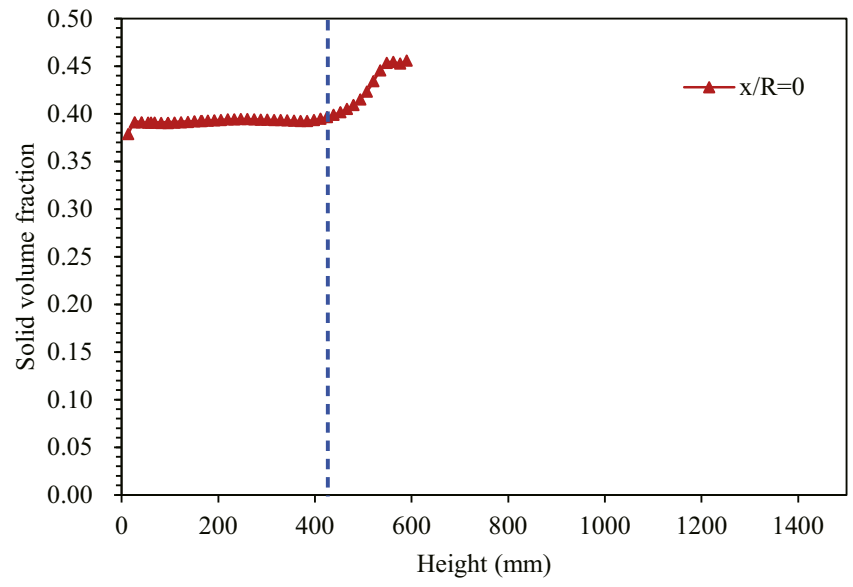

(b)

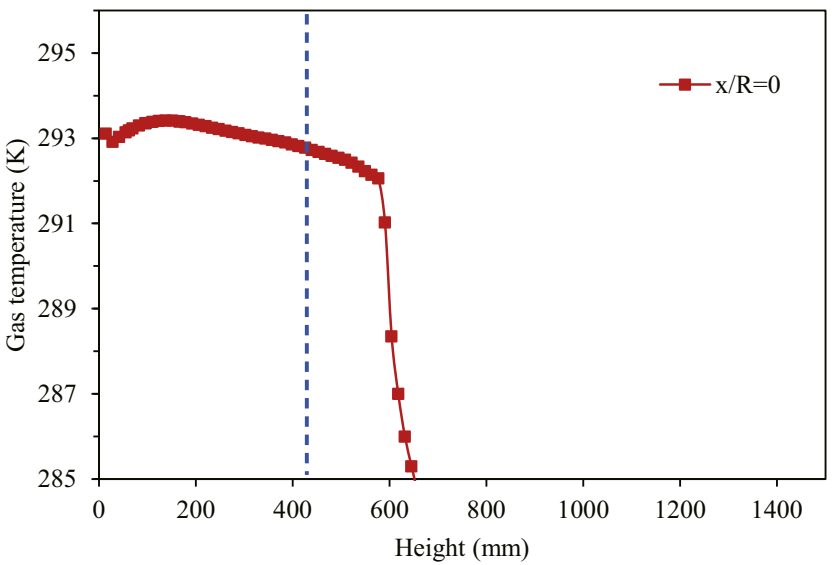

(d)

Fig. 16. Axial distributions of the (a) GH dissociation rate, (b) solid volume fraction, and (c) temperature of solid particles and (d) water at $x / R=0$ for $t=5 \mathrm{~s}$.

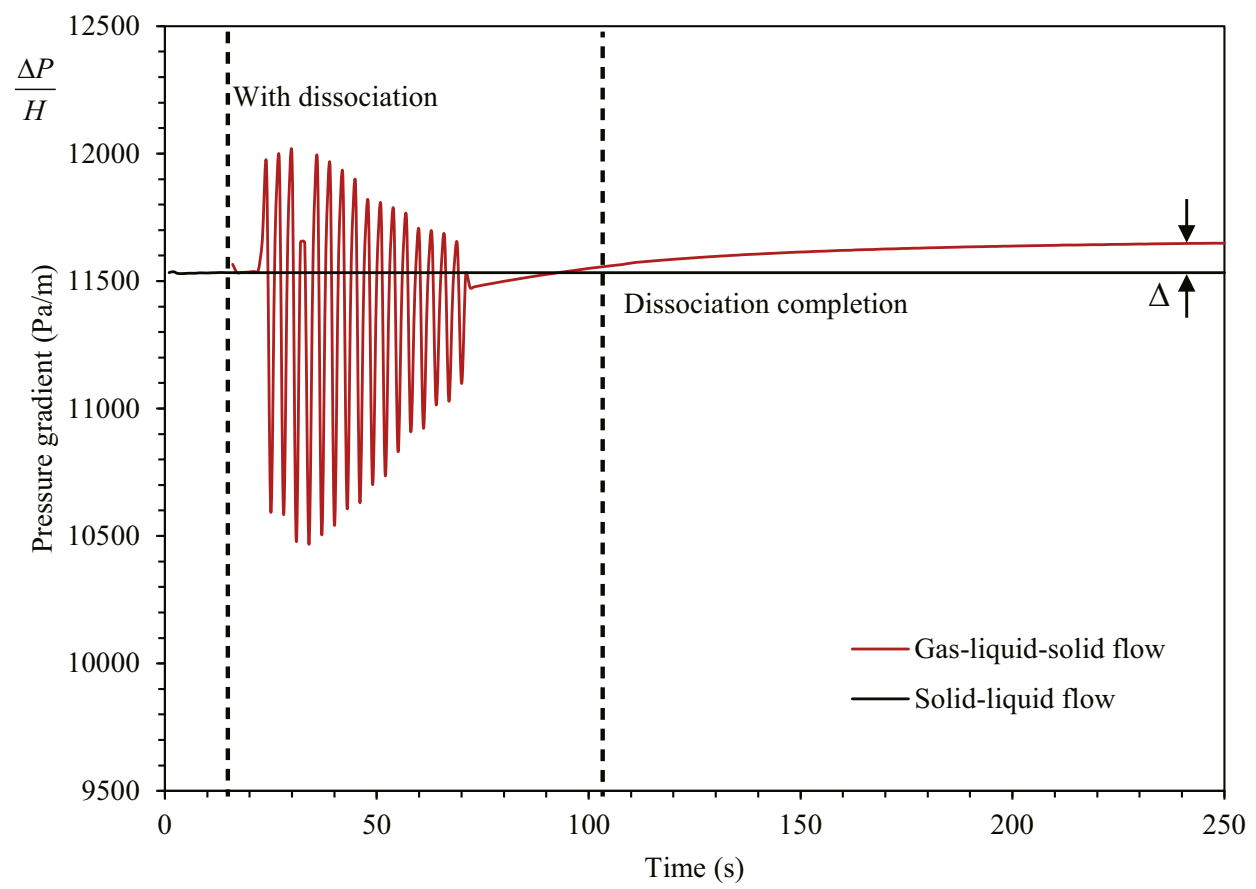

Fig. 17. Variation of pressure gradient in the pipe with time, $\mathrm{H}=1500 \mathrm{~mm}$. 
$103 \mathrm{~s}$, the GH has dissociated completely and the gas bubbles flow out of the pipe gradually. The pressure gradient in the pipe begins to exceed the pressure gradient of the solid-liquid flow and increases to a steady value. The difference of the pressure gradient between the solid-liquid flow and the gas-liquid-solid flow is caused by the increase in solid density after the GH dissociation. Fig. 18 shows the change in the solid density with time. The density of solid particles continues to increase during GH dissociation. Fig. 19 shows the variation of the expansion height of particles with time. The computed bed expansion ratio with the hydrate dis- sociation exhibits two stages divided by $t=62 \mathrm{~s}$. Before this, the bed expansion height increases with time. It decreases gradually to a stable state once the time exceeds $62 \mathrm{~s}$

The gas released by GH dissociation in GHBS particles leads to the fluctuation of the pressure gradient in the pipe, which helps lift the particles. However, the increase in the particle density caused by hydrate dissociation reduces the bed height. Hence, the particle expansion depends on the gas content and solid density. From $15 \mathrm{~s}$ to $62 \mathrm{~s}$, the lift effect of particle is greater than the sedimentation effect of particles due to the high gas content. After dissociation

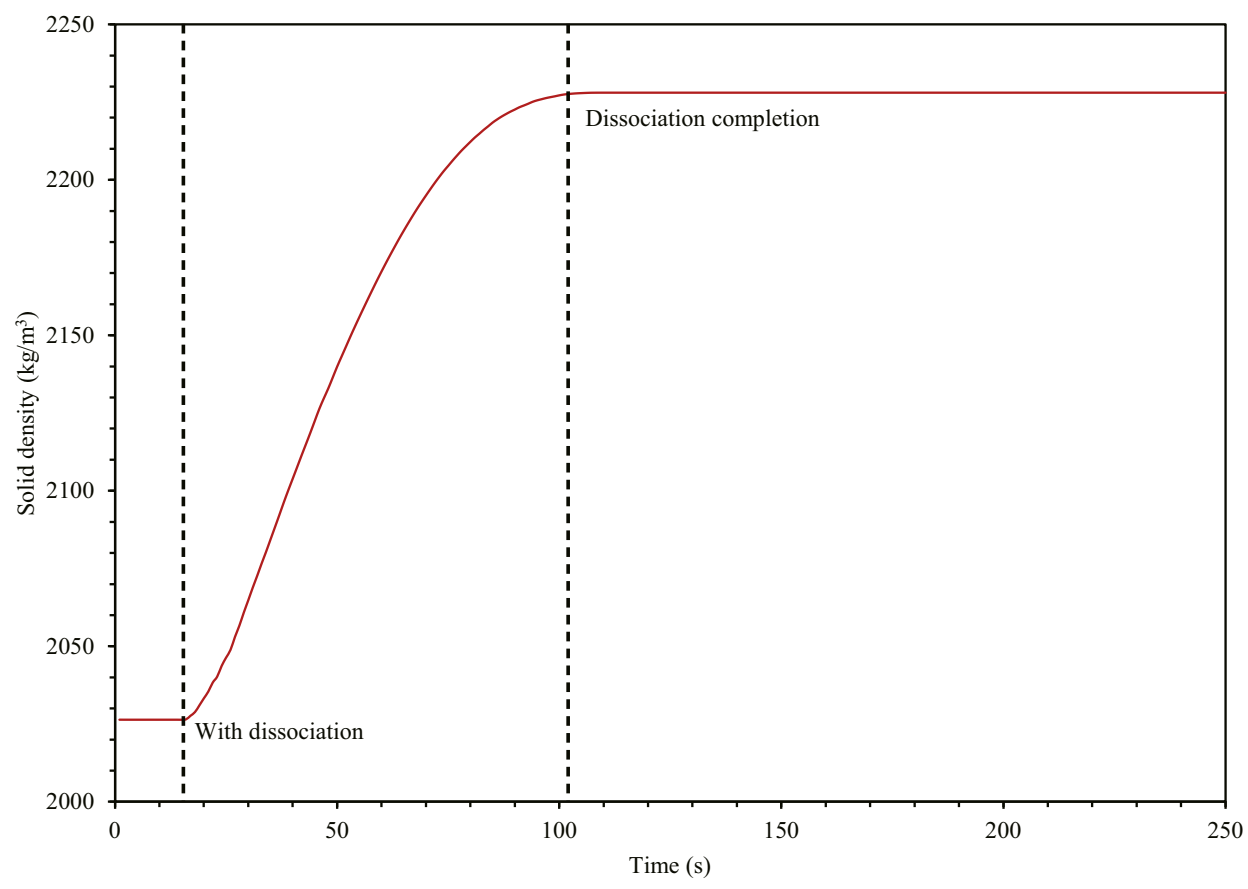

Fig. 18. Variation of the solid particles' density with time.

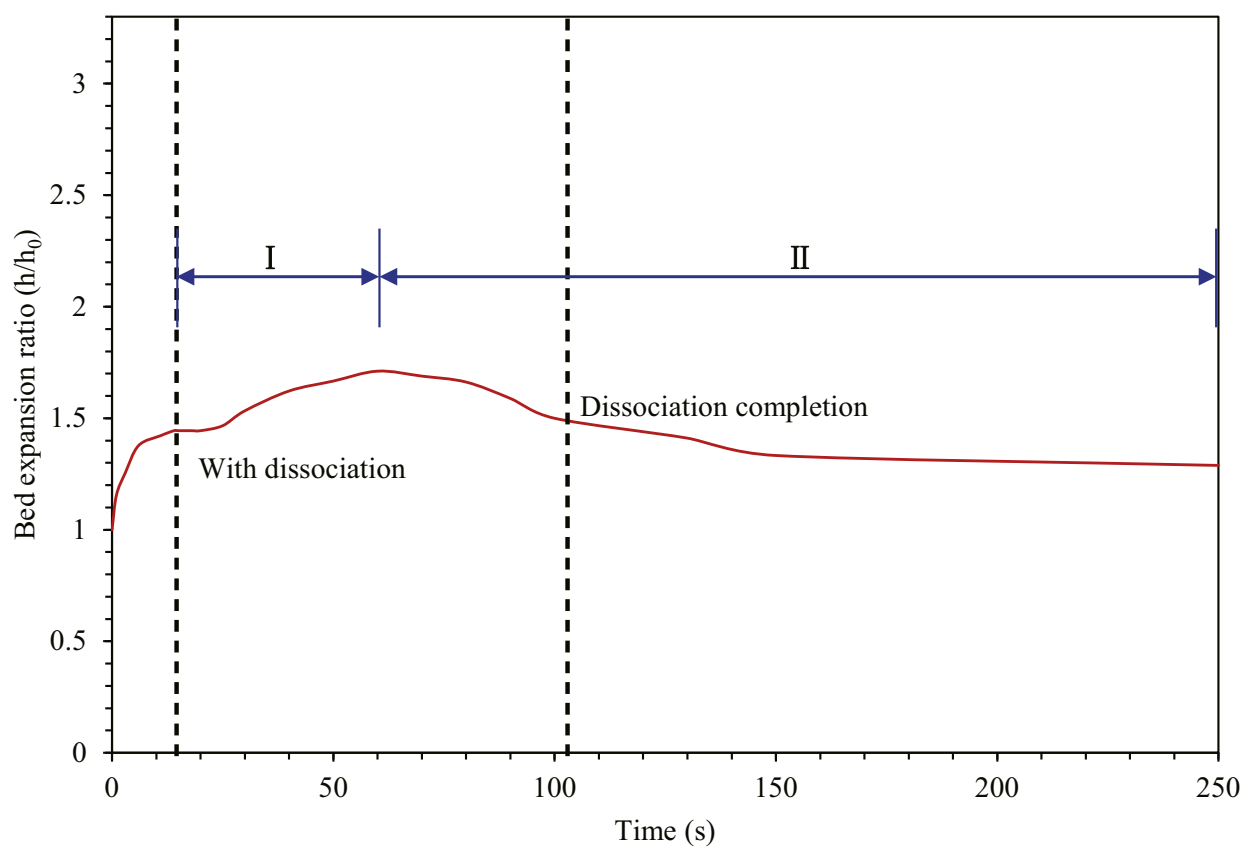

Fig. 19. Variation of bed expansion ratio in pipe with time, $h_{0}=450 \mathrm{~mm}$. 
completion, the particle sedimentation effect dominates the bed behavior, which leads to the bed expansion height decreases with time. When the gas volume fraction is zero, the bed expansion height is stable (Fig. 19).

The current three-phase flow model coupled with the GH dissociation can describe the changes in the multiphase flow behaviors in the pipe, such as the pressure gradient and the elevation of the particles. Considering that the hydrate dissociation kinetic model plays a decisive role in the formation of multiphase flow, in order to find more accurate multiphase flow behaviors, more experimental data are required to calibrate the kinetic parameters of the $\mathrm{GH}$ dissociation model used in this study.

\subsection{Effects of hydrate saturation on multiphase flow}

The simulations with various GH saturations are carried out to explore the effects of GH dissociation on the gas-liquid-solid flow.
The GH saturation is the ratio of the volume of hydrate to the total pore volume. In the following simulations, the porosity of GHBS particles is assumed to be 0.4 . The GH saturations are set as $20 \%$, $40 \%, 80 \%$, and $100 \%$. The relationship between GH saturation and GH mass fraction is shown in Table 6. Other settings are the same as in Table 4.

Fig. 20 shows the variation of pressure gradient along pipe at different GH saturation. The comparison with the pressure gradient of solid-liquid flow is also conducted. The pressure gradient fluctuation wave during $\mathrm{GH}$ dissociation varies with the GH saturation. The amplitude of such a wave increases with the increase in the GH saturation. The change in the pressure gradient corresponds to the bed expansion height. Fig. 21 shows the effect of different GH saturations on the bed expansion height. Compared with the solid-liquid flow, the expansion heights of the gas-liquid-solid flow with different hydrate saturations have experienced a process of rising and then decreasing. The final stable heights are lower

Table 6

Relationship between GH saturation and GH mass fraction.

\begin{tabular}{|c|c|c|c|c|}
\hline Case \# & Porosity & Hydrate saturation & Mass fraction of hydrate & Mass fraction of water \\
\hline Base case & $40 \%$ & $40 \%$ & $7.29 \%$ & $11.87 \%$ \\
\hline 1 & $40 \%$ & $20 \%$ & $3.63 \%$ & $15.77 \%$ \\
\hline 2 & $40 \%$ & $80 \%$ & $14.67 \%$ & $3.98 \%$ \\
\hline 3 & $40 \%$ & $100 \%$ & $18.40 \%$ & $0 \%$ \\
\hline
\end{tabular}

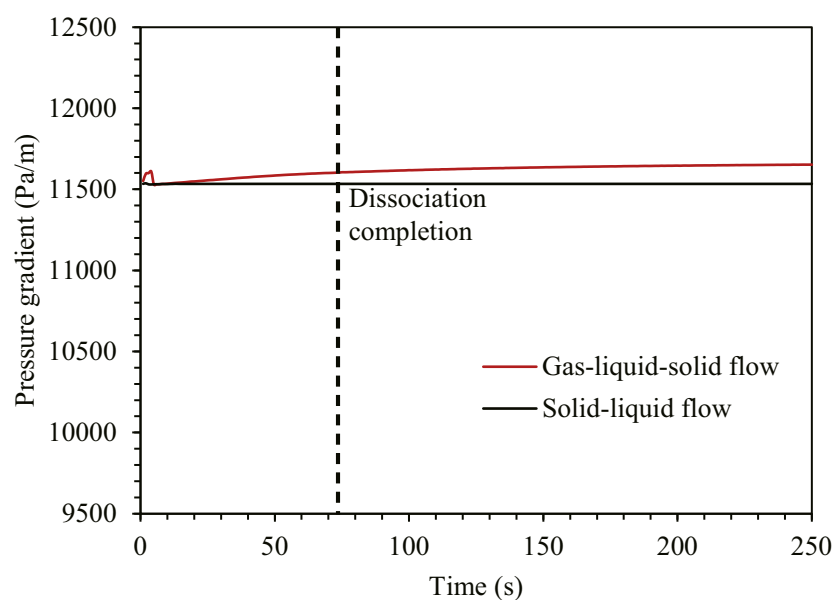

(a) $20 \%$

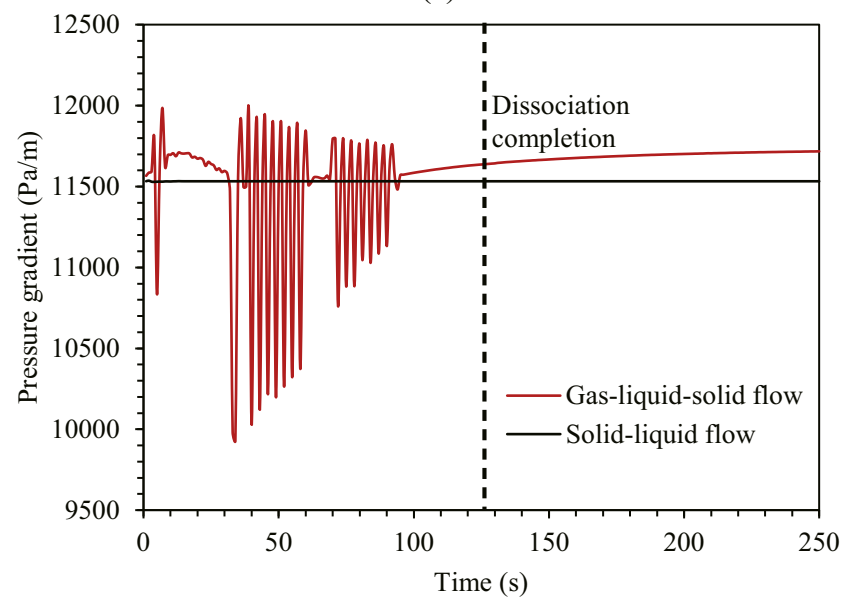

(c) $80 \%$

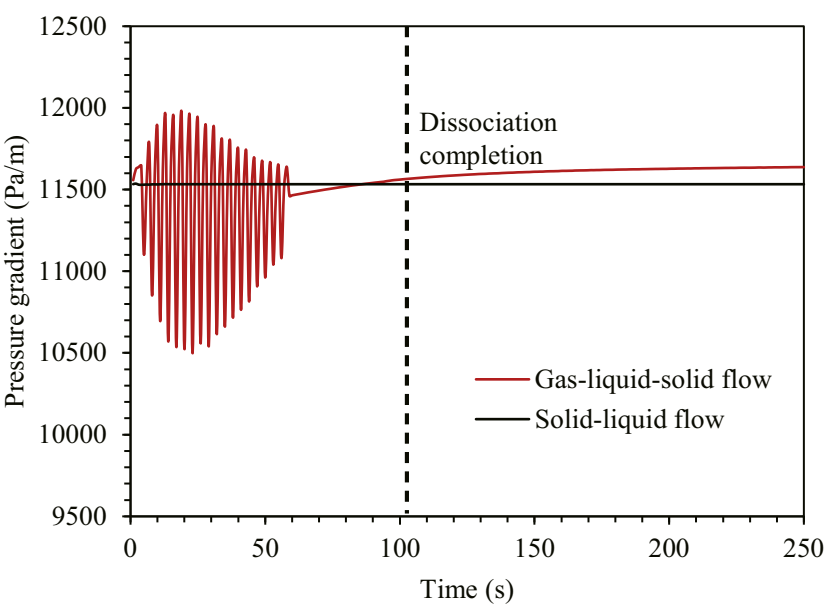

(b) $40 \%$

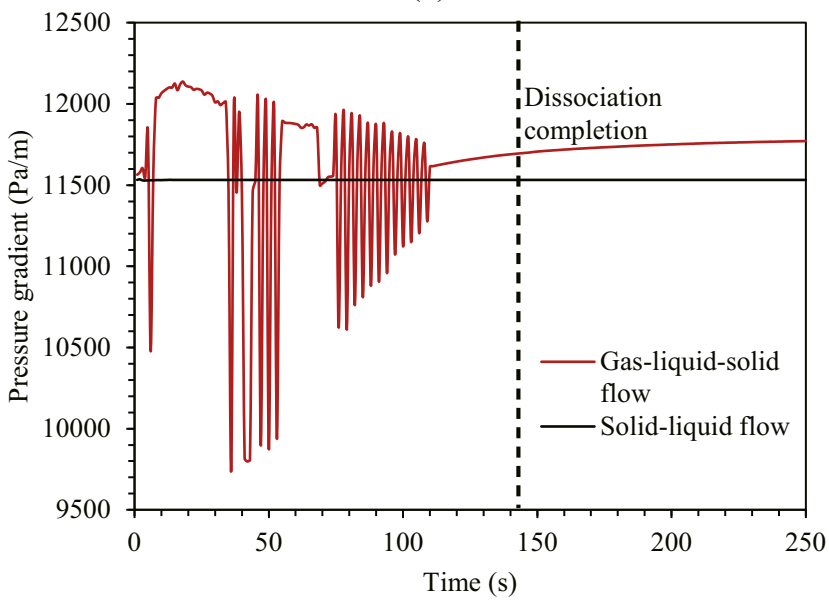

(d) $100 \%$

Fig. 20. Effect of different GH saturations on the pressure gradient in the pipe. (a) $20 \%$, (b) $40 \%$, (c) $80 \%$, (d) $100 \%$. 
than the stable height of solid-liquid flow due to the increase in solid density. Moreover, the expansion rate of the gas-liquid-solid flow with GH dissociation is no faster than that of the solid-liquid flow in the initial stage of dissociation. This may be caused by the gas production, which reduces the velocity of the water surrounding the particles. It is noted that the bed expansion becomes unstable when the GH saturation is $80 \%$ and $100 \%$, as shown in Fig. 22. It can be inferred that when the GH saturation is high or the amount

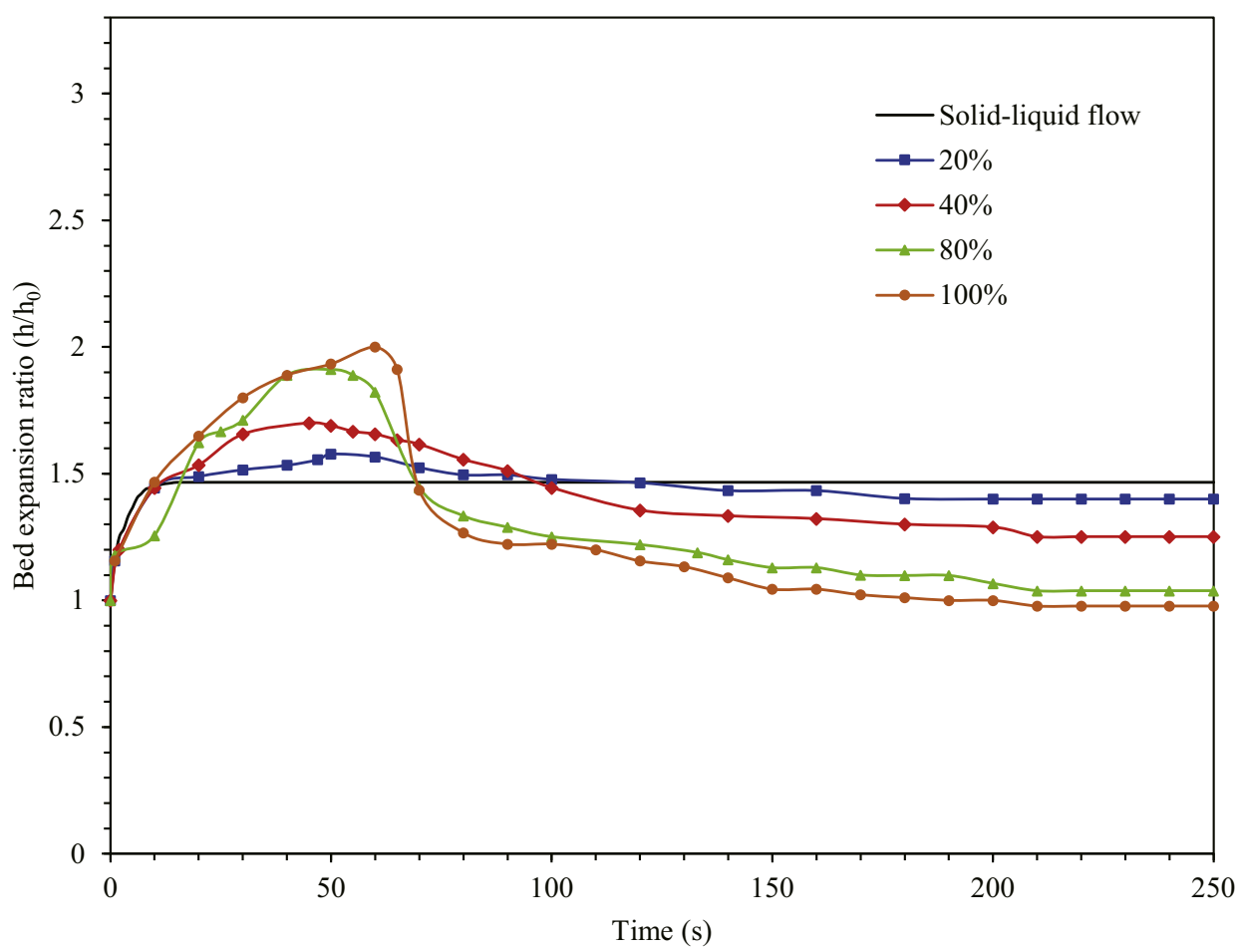

Fig. 21. Effect of different GH saturations on the bed expansion height in the pipe.
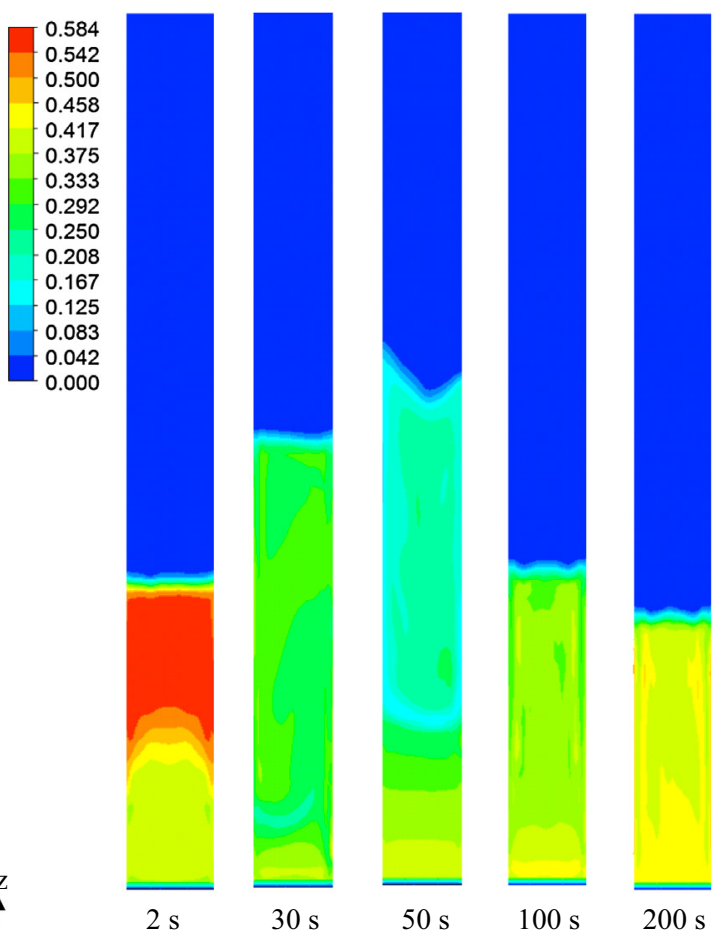

(a) $80 \%$

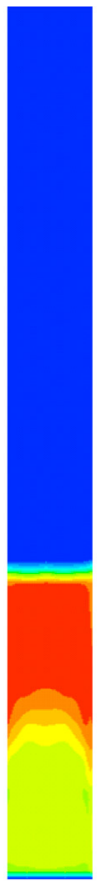

$2 \mathrm{~s}$

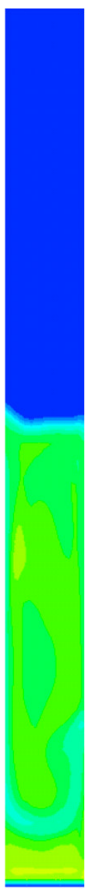

$30 \mathrm{~s}$

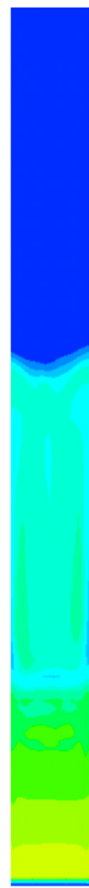

$50 \mathrm{~s}$

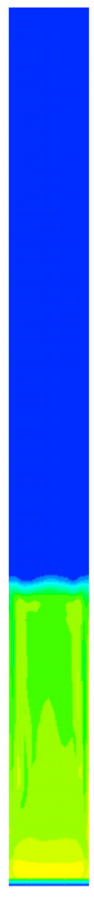

$100 \mathrm{~s}$

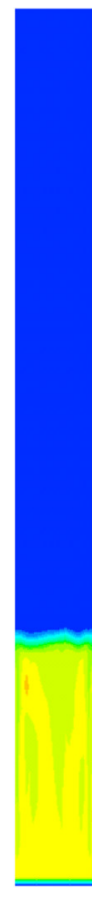

$200 \mathrm{~s}$

(b) $100 \%$

Fig. 22. Instantaneous distribution of the solid volume fraction for gas-liquid-solid three-phase flow with the GH saturation (a) $80 \%$ and (b) $100 \%$. 


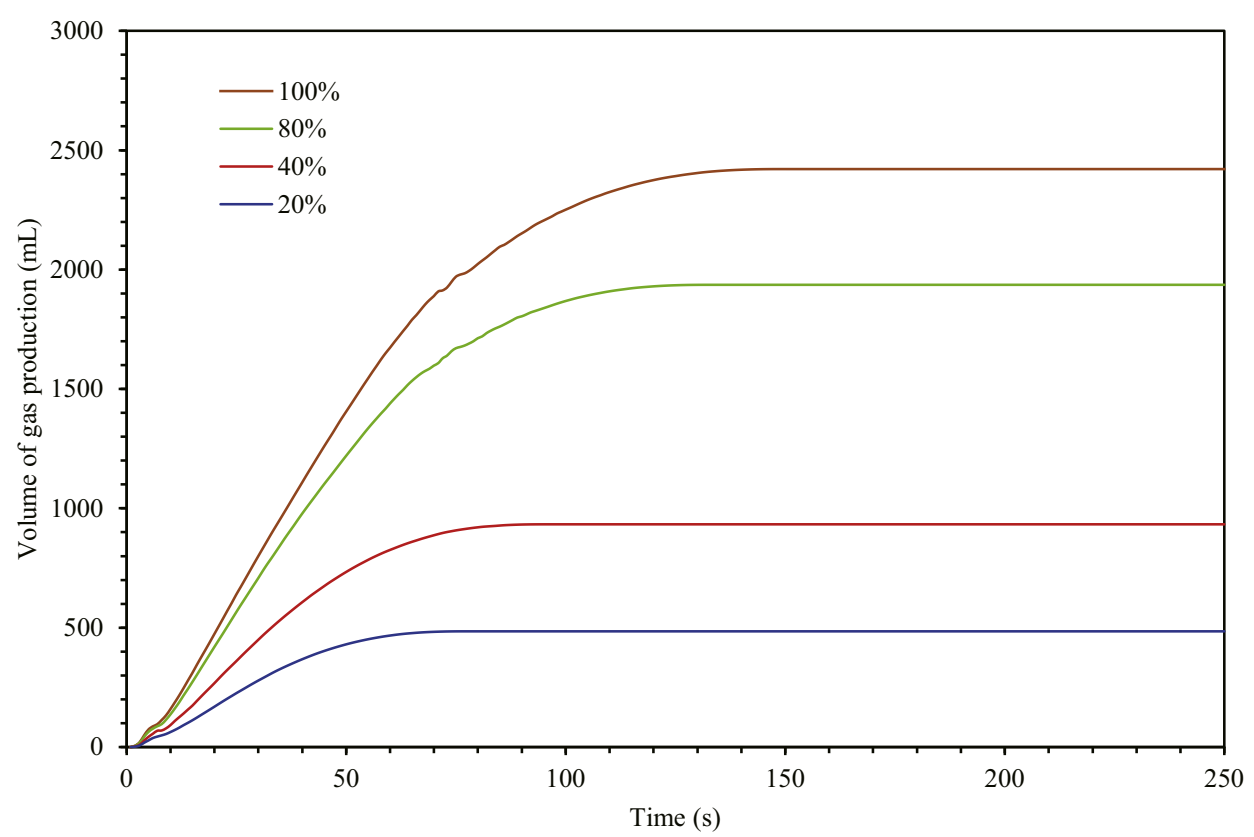

Fig. 23. Variation of gas production with time at different GH saturations.

of gas dissociated per unit time is large, the flow pattern in the pipe will change, even the gas channeling occurs, which greatly affects the safety of pipe transportation.

The variation of gas production with time at different $\mathrm{GH}$ saturations is studied, as shown in Fig. 23. It can be clearly observed that the dissociation rate increases with the increase in GH saturation. The durations for the GH saturation from $20 \%$ to $100 \%$ are $72 \mathrm{~s}$, $103 \mathrm{~s}, 127 \mathrm{~s}$, and $143 \mathrm{~s}$, respectively, and the cumulative gas volumes for different GH saturations are $484 \mathrm{~mL}, 933 \mathrm{~mL}, 1937 \mathrm{~mL}$, and $2420 \mathrm{~mL}$, respectively.

\section{Conclusion}

Many studies have been conducted on gas/liquid-solid twophase flow coupling with heat and mass transfer, but little attention has been paid to the behavior of gas-liquid-solid threephase flow in the presence of heat and mass transfer. Hence, in the present study, a three-dimensional numerical model is adopted within the framework of the CFD software FLUENT 16.2 to describe the gas-liquid-solid three-phase flow coupled with GH dissociation in GHBS particles in a vertical pipe. Based on the Eulerian three-fluid model, all three phases are treated as interpenetrating continua. The liquid phase flow is described in the standard $\kappa-\varepsilon$ turbulence model. The particle phase flow is described by the kinetic theory of granular flow (KTGF). A GH dissociation rate model in Arrhenius form is presented, considering the influence of the gas-liquid-solid three-phase flow on the dissociation rate. The hydrodynamics, heat and mass transfer, and GH dissociation are simultaneously considered.

Some salient conclusions can be drawn by the present simulation results:

(a) The model can effectively capture the phenomenon of GHBS particle dissociation and the transition from solid-liquid two-phase flow to gas-liquid-solid flow in the pipe. The changes in the flow characteristics in the vertical pipe, such as the distribution of the volume fraction, velocity, temperature, and the components of the solid phase, are also obtained.

(b) The pressure gradient along the pipe fluctuates violently and the expansion height of particles increases as the gas volume continues to grow compared with the liquid-solid twophase flow without GH dissociation.

(c) Higher slip velocity between the solid and the liquid phase leads to higher convective heat transfer efficiency but lower solid concentration, which then affects the GH dissociation rate. The dissociation rate is higher in the near-wall region and lower in the center region.

(d) The higher the GH saturation, the more intense the pressure gradient fluctuations, leading to greater bed expansion height and gas production. However, the flow instability caused by higher GH saturation may affect the safety of pipe transportation.

It is worth further studying the accurate GH dissociation process in GHBS particles under convective heat transfer conditions, and the optimization of continuous multiphase transportation.

\section{Acknowledgments}

This study is part of project No. 51639008 funded by the National Natural Science Foundation of China, and the Youth Innovation Promotion Association of Chinese Academy of Sciences No. 2017027.

\section{References}

Adamczyk, W.P., Kozolub, P., Wecel, G., Klimanek, A., Bialecki, R.A., Czakiert, T., 2014. Modeling oxy-fuel combustion in a 3D circulating fluidized bed using the hybrid Euler-Lagrange approach. Appl. Therm. Eng. 71, 266-275.

Armstrong, L.M., Gu, S., Luo, K.H., 2011. Effects of limestone calcination on the gasification processes in a BFB coal gasifier. Chem. Eng. J. 168, 848-860.

Askaripour, H., Dehkordi, A.M., 2016. Effects of initial static bed height on fractional conversion and bed pressure drop in tapered-in and tapered-out fluidized bed reactors. Int. J. Multiph. Flow 79, 50-61.

ANSYS Inc., 2015. ANSYS Fluent theory guide.

Bai, Y.H., Li, Q.P., Yu, X.C., Feng, G.Z., 2007. Numerical study on dissociation of gas hydrate of gas hydrate and its sensitivity to physical parameters. China Ocean Eng. 21 (4), 625-636.

Baltussen, M.W., Kuipers, J.A.M., Deen, N.G., 2017. Direct numerical simulation of effective drag in dense gas-liquid-solid three-phase flows. Chem. Eng. Sci. 158, $561-568$.

Baniasadi, Mehdi, Baniasadi, Maryam, Peters, Bernhard, 2018. Coupled CFD-DEM with heat and mass transfer to investigate the melting of a granular packed bed. Chem. Eng. Sci. 178, 136-145. 
Behjat, Y., Shahhosseini, S., Marvast, M.A., 2011. CFD analysis of hydrodynamic, heat transfer and reaction of three phase riser reactor. Chem. Eng. Res. Des. 89 (7), 978-989.

Cornejo, P., Farías, O., 2011. Mathematical modeling of coal gasification in a fluidized bed reactor using a Eulerian granular description. Int. J. Chem. Reactor Eng. 9 (1), 42-43.

Dickens, G.R., Quinby, H.M.S., 1994. Methane hydrate stability in seawater. Geophys. Res. Lett. 21 (19), 2115-2118.

Friend, D.G., Ely, J.F., Ingham, H., 1989. Thermo-physical properties of methane. J. Phys. Chem. Ref. Data 18 (2), 583-638.

Gerber, S., Behrendt, F., Oevermann, M., 2010. An Eulerian modeling approach of wood gasification in a bubbling fluidized bed reactor using char as bed material. Fuel 89, 2903-2917.

Hamidipour, M., Chen, J., Faïçal, L., 2012. CFD study on hydrodynamics in threephase fluidized beds-application of turbulence models and experimental validation. Chem. Eng. Sci. 78, 167-180.

Hong, H., Pooladi-Darvish, M., Bishnoi, P.R., 2003. Analytical modelling of gas production from hydrates in porous media. J. Can. Pet. Technol. 42 (11), 45-56.

Jain, V., Kalo, L., Kumar, D., Pant, H.J., Upadhyay, R.K., 2017. Experimental and numerical investigation of liquid-solid binary fluidized beds: radioactive particle tracking technique and dense discrete phase model simulations. Particuology 33, 112-122.

Johnson, P.C., Jackson, R., 1987. Frictional-collisional constitutive relations for granular Materials, with application to plane shearing. J. Fluid Mech. 176, 6793.

Klimanek, A., Adamczyk, W., Katelbach-Wozniak, A., Wecel, G., Szlek, A., 2015. Towards a hybrid Eulerian-Lagrangian CFD modeling of coal gasification in a circulating fluidized bed reactor. Fuel 152, 131-137.

Kvenvolden, K.A., Lorenson, T.D., 2001. The global occurrence of natural gas hydrate. Geophys. Monogr. 124, 3-18.

Lanuder, B.E., Spalding, D.B., 1974. The numerical computation of turbulent flows. Comput. Methods Appl. Mech. Eng. 3, 269-289.

Li, P., Zhang, X.H., Lu, X.B., Liu, L.L., Liu, C.L., 2016. Study on gas hydrate dissociation in small bodies of hydrate-bearing sediments under water-heating condition. In: 26th Annual International Ocean and Polar Engineering Conference, ISOPE. Rhodes, Greece. June 26, 2016 - July 1, 2016.

Li, P., Zhang, X.H., Lu, X.B., 2018. Dissociation Behaviors of $\mathrm{CO}_{2}$ Hydrate-Bearing Sediment Particle during Settling in Water. Energies 11 (11), 2896.

Limtrakul, S., Chen, J., Ramachandran, P.A., Duduković, M.P., 2005. Solids motion and holdup profiles in liquid fluidized beds. Chem. Eng. Sci. 60, 1889-1900.

Liu, D.Y., 1993. Fluid Dynamics of Two-Phase Systems. Higher Education Press. in Chinese.

Liu, H., Elkamel, A., Lohi, A., Biglari, M., 2013. Computational fluid dynamics modeling of biomass gasification in circulating fluidized-bed reactor using the Eulerian-Eulerian approach. Ind. Eng. Chem. Res. 52, 18162-18174.

Loha, C., Chattopadhyay, H., Chatterjee, P.K., 2014. Three dimensional kinetic modeling of fluidized bed biomass gasification. Chem. Eng. Sci. 109, 53-64.

Ma, Y., Liu, M., Zhang, Y., 2018. An improved meso-scale flow model of gas-liquidsolid fluidized beds. Chem. Eng. Sci. 179, 243-256.

Makogon, Y.F., 1997. Hydrates of Hydrocarbon. PennWell Publishing Company, USA.

Makogon, Y.F., Holditch, S.A., Makogon, T.Y., 2005. Russian field illustrates gashydrate production. Oil Gas J. 103, 43-47.

Moridis, G.J., Collett, T.S., Dallimore, S.R., 2004. Numerical studies of gas production from several $\mathrm{CH}_{4}$ hydrate zones at the Mallik site, Mackenzie Delta. Canada. J. Petrol. Sci. Eng. 43, 219-238.

Murthy, B.N., Ghadge, R.S., Joshi, J.B., 2007. CFD simulations of gas-liquid-solid stirred reactor: prediction of critical impeller speed for solid suspension. Chem. Eng. Sci. 62 (24), 7184-7195.
Oyama, H., Konno, Y., Masuda, Y., Narita, H., 2009. Dependence of depressurization induced dissociation of methane hydrate bearing laboratory cores on heat transfer. Energy Fuels 23 (10), 4995-5002.

Pan, H., Chen, X.Z., Liang, X.F., Zhu, L.T., Luo, Z.H., 2016. CFD simulations of gasliquid-solid flow in fluidized bed reactors-A review. Powder Technol. 299, 235258.

Panneerselvam, R., Savithri, S., Surender, G.D., 2007. CFD based investigations on hydrodynamics and energy dissipation due to solid motion in liquid fluidized bed. Chem. Eng. J. 132 (1-3), 159-171.

Panneerselvam, R., Savithri, S., Surender, G.D., 2009. CFD simulation of hydrodynamics of gas-liquid-solid fluidised bed reactor. Chem. Eng. Sci. 64 (6), 1119-1135.

Qin, Z., Suckale, J., 2017. Direct numerical simulations of gas-solid-liquid interactions in dilute fluids. Int. J. Multiph. Flow 96, 34-47.

Rafique, M., Chen, P., Duduković, M.P., 2004. Computational modeling of gas-liquid flow in bubble columns. Rev. Chem. Eng. 20 (3-4), 225-375.

Rueff, R.M., Sloan, E.D., Yesavage, V.F., 1988. Heat capacity and heat of dissociation of methane hydrates. AIChE J. 34 (9), 1468-1476.

Sean, W.Y., Sato, T., Yamasaki, A., Kiyono, F., 2007. CFD and experimental study on methane hydrate dissociation Part I. Dissociation under water flow. AIChE J. 53, 262-274.

Selim, M.S., Sloan, E.D., 1989. Heat and mass transfer during the dissociation of hydrates in porous media. AIChE J. 35 (6), 1049-1052.

Snider, D., Banerjee, S., 2010. Heterogeneous gas chemistry in the CPFD EulerianLagrangian numerical scheme (ozone decomposition). Powder Technol. 199 (1), 100-106.

Sokolichin, A., Eigenberger, G., Lapin, A., 2004. Simulation of buoyancy driven bubbly flow: established simplifications and open questions. AIChE J. 50, $24-45$.

Wagner, W., Pruss, A., 2002. The IAPWS formulation 1995 for the thermodynamic properties of ordinary water substance for general and scientific use. J. Phys. Chem. Ref. Data 31 (2), 387-535.

Wang, X., Ding, J., Ren, N.Q., Liu, B.F., Guo, W.Q., 2009. CFD simulation of an expanded granular sludge bed (EGSB) reactor for biohydrogen production. Int. J. Hydrogen Energy 34, 9686-9695.

Wang, Z.Y., Sun, B.J., 2009. Annular multiphase flow behavior during deep water drilling and the effect of hydrate phase transition. Pet. Sci. 6 (1), 57-63. in Chinese.

Wei, N., Sun, W., Meng, Y., Zhou, S., Li, G., Guo, P., Dong, K., Li, Q., 2016. Sensitivity analysis of multiphase flow in annulus during drilling of marine natural gas hydrate reservoirs. J. Nat. Gas Sci. Eng. 36, 692-707. https://doi.org/10.1016/j. jngse.2016.11.007.

Wu, Y., Liu, D.Y., Duan, L.B., Ma, J.L., Xiong, J., Chen, X.P., 2018. Three-dimensional CFD simulation of oxy-fuel combustion in a circulating fluidized bed with warm flue gas recycle. Fuel 216, 596-611.

Yin, Z., Chong, Z.R., Tan, H.K., Linga, P., 2016. Reviews of gas hydrate dissociation kinetic models for energy recovery. J. Nat. Gas Sci. Eng. 35, 1362-1387.

Zhang, W., Bai, F.L., Shao, M.J., Tian, Q.N., 2017. Progress of offshore natural gas hydrate production tests in Japan and implications. Mar. Geol. Quater. Geol. 37 (5), 27-33. in Chinese.

Zhang, X.H., Lu, X.B., 2016. A new exploitation method for gas hydrate in shallow stratum: mechanical-thermal method. Chin. J. Theor. Appl. Mech. 48 (5), 12381246. in Chinese.

Zhang, X.H., Lu, X.B., Liu, L.L., 2014. Advances in natural gas hydrate recovery methods. Prog. Geophys. 29 (2), 0858-0869. in Chinese.

Zhong, W., Yu, A., Zhou, G., Xie, J., Zhang, H., 2016. CFD simulation of dense particulate reaction system: approaches, recent advances and applications, Chem. Eng. Sci. 140, 16-43. 